\title{
Aerosol indirect forcing in a global model with particle nucleation
}

\author{
M. Wang and J. E. Penner \\ Department of Atmospheric, Oceanic, and Space Sciences, University of Michigan, Ann Arbor, Michigan, USA
}

Received: 10 June 2008 - Published in Atmos. Chem. Phys. Discuss.: 22 July 2008

Revised: 17 November 2008 - Accepted: 8 December 2008 - Published: 14 January 2009

\begin{abstract}
The number concentration of cloud condensation nuclei $(\mathrm{CCN})$ formed as a result of anthropogenic emissions is a key uncertainty in the study of aerosol indirect forcing and global climate change. Here, we use a global aerosol model that includes an empirical boundary layer nucleation mechanism, the use of primary-emitted sulfate particles to represent sub-grid scale nucleation, as well as binary homogeneous nucleation to explore how nucleation affects the $\mathrm{CCN}$ concentration and the first aerosol indirect effect (AIE). The inclusion of the boundary layer nucleation scheme increases the global average $\mathrm{CCN}$ concentrations in the boundary layer by $31.4 \%$ when no primary-emitted sulfate particles are included and by $5.3 \%$ when they are included. Particle formation with the boundary layer nucleation scheme decreases the first indirect forcing over ocean, and increases the first indirect forcing over land when primary sulfate particles are included. This suggests that whether particle formation from aerosol nucleation increases or decreases aerosol indirect effects largely depends on the relative change of primary particles and $\mathrm{SO}_{2}$ emissions from the preindustrial to the present day atmosphere. Including primary-emitted sulfate particle significantly increases both the anthropogenic fraction of CCN concentrations and the first aerosol indirect forcing. The forcing from various treatments of aerosol nucleation ranges from -1.22 to $-2.03 \mathrm{w} / \mathrm{m}^{2}$. This large variation shows the importance of better quantifying aerosol nucleation mechanisms for the prediction of CCN concentrations and aerosol indirect effects.
\end{abstract}

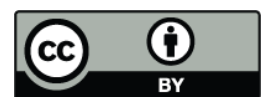

Correspondence to: M. Wang (minghuai@umich.edu)

\section{Introduction}

Atmospheric aerosols are an important component of the global climate system. One of the primary effects of aerosols is to modify cloud properties by acting as cloud condensation nuclei (CCN). This so-called aerosol indirect effect can be split into the "first indirect effect" - the effect of aerosol particles on initial cloud droplet size and cloud albedo - and the "second indirect effect" - the response of the cloud morphology to changes in the precipitation efficiency of the cloud (Forster et al., 2007). This aerosol indirect effect is one of the largest uncertainties in our understanding of climate change. One major challenge in the study of the aerosol indirect effect is to determine the source of the $\mathrm{CCN}$-size particles, which involves the accurate treatment of both aerosol microphysics and large scale atmosphere dynamics (Raes et al., 2000).

The processes that determine the number of $\mathrm{CCN}$ particles include emissions, photochemistry, nucleation, coagulation, condensation, and wet removal. Some particles are primary particles, i.e. emitted directly from sources, such as carbonaceous particles from open fires (Ito and Penner, 2005), sea salt particles from the bubble-bursting process of whitecaps (Clarke et al., 2006), and dust particles from wind erosion of dry soils (Ginoux et al., 2001). Some of these particles are large enough to act as $\mathrm{CCN}$, such as some sea salt particles (Clarke et al., 2006), but other particles, such as hydrophobic soot particles, must first add soluble compounds and grow by condensation and coagulation to sizes that are large enough to act as CCN (Rissler et al., 2006). Secondary particles may be generated from the nucleation of gas phase species, such as sulfuric acid gas and water vapor (Kulmala et al., 2007). These freshly nucleated particles begin as nanometer sized particles, and need substantial growth to become $\mathrm{CCN}$-sized particles. New particle formation events capable of producing $\mathrm{CCN}$-size particles have been observed at locations including the sub-Arctic boreal forest (Lihavainen et al., 2003), coastal areas (O’Dowd et

Published by Copernicus Publications on behalf of the European Geosciences Union. 
al., 2002a), in continental (McNaughton et al., 2004; Laaksonen et al., 2005) and cloud outflow regions (Twohy et al., 2002), and in the upper free troposphere (Singh et al., 2002). Primary particles and secondary particles interact with each other by coagulation, and compete for gas phase species which may condense or form new particles through nucleation.

Cloud processing is another important microphysical process that may produce CCN-sized particles (Hoppel et al., 1994). In an environment with high supersaturations, some ultrafine particles ( $<0.05 \mu \mathrm{m}$ in radius) can activate into nonprecipitating cloud droplets. Once a droplet is formed, aqueous oxidation of compounds within the drop will add mass to the pre-existing particles. When the cloud droplets evaporate, the residual aerosol particles are larger than original aerosol particles and can be activated more readily with a more modest supersaturation.

The concentration of CCN-sized particles that are available for cloud formation also depends on the transport between different atmospheric compartments (e.g. the marine boundary layer (MBL) and the free troposphere (FT)) because the residence time of aerosols within a typical atmospheric compartment is shorter than the characteristic time of many aerosol microphysical processes (Raes et al., 2000). For example, observations have shown that subsidence from the FT may be an important process controlling MBL aerosol number concentrations (Clarke et al., 1996, 2006; Van Dingenen, 1999). Clarke et al. (2006) estimated that entrainment from the FT can provide $35 \%-80 \%$ of the CCN flux into the MBL over regions between $40^{\circ} \mathrm{S}$ and $40^{\circ} \mathrm{N}$ with the rest from sea salt aerosol.

Unraveling the role of these complicated processes in determining $\mathrm{CCN}$-sized particles requires a global model that can account for both aerosol microphysical processes and large and small scale transport (Raes et al., 2000). In order to meet this need, global aerosol models with detailed aerosol microphysics modules have been recently developed (Wilson et al., 2001; Adams and Seinfeld, 2002; Gong et al., 2003; Easter et al., 2004; Lauer et al., 2005; Liu et al., 2005; Spracklen et al., 2005a; Stier et al., 2005). Generally, these aerosol microphysics modules include the formation of new aerosol particles (nucleation) from gas phase species (e.g., sulfuric acid gas and water vapor), the condensation of volatile gases on preexisting aerosol particles, the coagulation of aerosol particles, and the cloud processing of the aerosol particles. The inclusion of these microphysical processes in a global aerosol model permits the model to predict the formation and cycling of aerosols in the global atmosphere and to determine the source of $\mathrm{CCN}$-sized particles.

Several studies have used these global aerosol models to investigate how different sources contribute to $\mathrm{CCN}$ concentrations. Adams and Seinfeld $(2002,2003)$ used a model that only included sulfate and showed that primary emissions of sulfate were more efficient at increasing $\mathrm{CCN}$ concentration per unit mass of $\mathrm{SO}_{2}$ emissions than gas-phase emis- sions. Pierce and Adams (2006) and Pierce et al. (2007) extended the Adams and Seinfeld model, adding primaryemitted aerosol particles from sea salt and carbonaceous aerosols. Pierce and Adams (2006) showed that including the emissions of ultrafine sea salt $(<0.05 \mu \mathrm{m}$ in radius $)$ can increase $\mathrm{CCN}$ concentrations at $0.2 \%$ supersaturation over the Southern Ocean by $20 \%$ to $60 \%$, depending on the sea salt emission parameterization which was used. Assuming an internal mixture of sulfate, sea salt, black carbon (BC) and organic matter (OM) in their model, Pierce et al. (2007) showed that the inclusion of carbonaceous aerosol particles can increase $\mathrm{CCN}$ concentrations (at $0.2 \%$ supersaturation) by $65-90 \%$ in the globally averaged surface layer depending on the carbonaceous emissions inventory used. In another study, Stier et al. (2006) included all major aerosol types and separately tracked soluble and insoluble particles and found that the column integrated soluble accumulation mode number concentration only decreased by $4.6 \%$ when anthropogenic carbonaceous emissions were excluded. In contrast, when anthropogenic emissions from both carbonaceous particles and sulfur were excluded, the column integrated soluble accumulation mode number concentration was decreased by $42.3 \%$. Spracklen et al. (2005a) used a model that only included sulfate and sea salt aerosols and simulated a larger decrease $(60 \%)$ in the $\mathrm{CCN}$ concentration at the surface when anthropogenic sources of sulfur were excluded. They also found that in the tropical oceanic marine boundary layer, sea spray contributes less than $10 \%$ of the total $\mathrm{CCN}$ and that the remaining $90 \%$ were derived mostly from sulfate particles that formed in the FT by binary homogeneous nucleation (BHN).

The model studies summarized above only considered binary homogenous nucleation (BHN). Although BHN can explain observed nucleation rates in the upper troposphere, it can not explain the observed nucleation rates in the boundary layer (e.g., Clarke et al., 1998). Several nucleation mechanisms have been suggested to explain boundary layer nucleation events (Kulmala et al., 2006; Sihto et al., 2006; Yu, 2006). Spracklen et al. (2006) include a boundary layer nucleation mechanism from Kulmala et al. (2006) in their global aerosol model and studied its effect on CCN concentrations (Spracklen et al., 2008). They demonstrated that the inclusion of the boundary layer nucleation scheme improves the comparison of the simulated nucleation events with observations in Hyytiälä, Finland, and improves the simulated particle size distribution and total particle number concentrations at three continental sites in Europe. Their global calculation also showed that boundary layer nucleation increases springtime boundary layer global mean $\mathrm{CCN}$ concentrations at $0.2 \%$ supersaturation by $3-20 \%$.

Large uncertainties remain in these model studies, however, especially in terms of the representation of primaryemitted particles. For example, Pierce et al. (2007) assumed that all carbonaceous aerosols were emitted in a size distribution with a number median diameter $\left(\mathrm{d}_{g}\right)$ of $0.023 \mu \mathrm{m}$ 
and a geometric standard deviation $(\sigma)$ of 2.00, while Stier et al. (2006) assumed a $\mathrm{d}_{g}$ of $0.06 \mu \mathrm{m}$ for carbonaceous aerosols from fossil-fuel and bio-fuel emissions and $\mathrm{a}_{g}$ of $0.15 \mu \mathrm{m}$ for those from vegetation fires with a $\sigma$ of 1.59 for all carbonaceous aerosols. These models also differ with respect to whether or not primary-emitted sulfate particles were included. Spracklen et al. (2005a, 2006) did not include any primary-emitted sulfate particles, while Stier et al. (2006), Pierce et al. (2007) and Spracklen et al. (2008) included these particles, but assumed different amounts and sizes for the emitted particulate sulfate.

More importantly, the effects of including different sources of CCN particles in models on the estimation of the aerosol indirect forcing have not been studied. Several studies have used the size-resolved aerosol composition predicted from their aerosol models to estimate the aerosol indirect effect (Ghan et al., 2001a; Lohmann et al., 2007; Storelvmo et al., 2006). But they did not examine how different treatments in the prediction of the aerosol size and number concentration affect the estimation of the first indirect forcing. Ghan et al. (2001a) showed that the aerosol indirect forcing calculated on the basis of their predicted aerosol size was smaller than that calculated on the basis of a prescribed size distribution, because anthropogenic sulfate contributed less to the simulated CCN particles in the case of the predicted aerosol size due to its condensation on other primary particles. Their conclusion, however, may be affected by the prescribed size chosen in their sensitivity test because, as noted in Chen and Penner (2005), the choice of the prescribed aerosol size has a large impact on the aerosol indirect forcing. Furthermore, their conclusion was drawn based on the aerosol indirect forcing from anthropogenic sulfate only. The concurrent increase in both anthropogenic sulfate and other non-sulfate aerosols may have different effects (Stier et al. 2006). Moreover, they did not investigate how the treatment of individual processes affect the calculated aerosol indirect forcing, e.g., how the primary-emitted sulfate particles included in their model affect the simulated aerosol indirect forcing.

We have recently developed a global aerosol model (Liu et al., 2005) which has been coupled to an atmospheric circulation model (Wang et al., 2009, hereafter Wang09). We showed that the inclusion of a boundary layer nucleation mechanism provides a better agreement with long-term observations of aerosol size distributions than do models that only include primary-emitted sulfate or BHN, especially over the MBL and over the Southern Hemisphere (SH). We also showed that the simulated effect of the boundary layer nucleation on the aerosol number concentration depends on whether primary-emitted sulfate particles are or are not included.

Here we extend the work of Wang09. The goals of this study are threefold: 1) to study the effect of including a boundary layer nucleation mechanism on $\mathrm{CCN}$ concentrations; 2) to revisit the effects of BHN in the FT and primaryemitted sulfate particles on $\mathrm{CCN}$ concentrations given the new context of the boundary layer nucleation mechanism included in the model; and 3) to further examine the effect of nucleation and the emission of primary sulfate particles on the indirect forcing by anthropogenic aerosols. Section 2 describes our methods. The global mass budget for all cases is described in Sect. 3. The effects on simulated CCN concentrations are explored in Sect. 4. The effects on the anthropogenic fraction of CCN are presented in Sect. 5. Cloud droplet number concentration and the first indirect effect are explored in Sect. 6. Finally, Sect. 7 presents a discussion and our conclusions.

\section{Methods}

\subsection{The coupled IMPACT-CAM model}

The model used here consists of two components (Wang09): the NCAR CAM3 atmospheric circulation model (Collins et al., 2006a), and the LLNL/Umich IMPACT aerosol model (Liu et al., 2005). The aerosol model component (IMPACT) includes an aerosol microphysics module that simulates the dynamics of the sulfate aerosol size distribution (nucleation, condensation, coagulation) and its interactions with primary emitted non-sulfate aerosols: OM, BC, dust and sea salt (Herzog et al., 2004). Both the mass and number of pure sulfate aerosol in an arbitrary number of modes are predicted. Herzog et al. (2004) showed that a mode representation for pure sulfate aerosols is able to capture the expected variability in the aerosol size distribution, given the estimated formation rates of gaseous $\mathrm{H}_{2} \mathrm{SO}_{4}$, and that the results from the mode representation compare well with that of a sectional model. In addition, the mode representation is computationally more efficient. Here we chose the two mode version of the model which includes a nucleation/Aitken mode $(\mathrm{r}<0.05 \mu \mathrm{m})$ and an accumulation mode $(\mathrm{r}>0.05 \mu \mathrm{m})$. Non-sulfate aerosols are assumed to follow predefined background size distributions (see Table 1 and Liu et al., 2005). Sulfuric acid gas $-\mathrm{H}_{2} \mathrm{SO}_{4}(\mathrm{~g})$ - is produced from the gas phase oxidation of DMS and $\mathrm{SO}_{2} \cdot \mathrm{H}_{2} \mathrm{SO}_{4}(\mathrm{~g})$ can nucleate to form new sulfate particles in the nucleation mode or can condense onto preexisting sulfate or non-sulfate aerosol particles. Sulfate aerosol particles can also coagulate with other particles. The hydrophilic and hydrophobic properties of non-sulfate aerosols are determined by the amount of sulfate coating that is produced through coagulation and condensation. The aqueous production of sulfate is equally distributed among the hygroscopic aerosol particles that are larger than $0.05 \mu \mathrm{m}$ in radius.

The atmospheric general circulation model (GCM) component (NCAR CAM3) is a part of the Community Climate System Model (CCSM3) (Collins et al., 2006b). Cloud water and cloud ice are separate prognostic variables in CAM3, which makes it possible to treat the difference in radiative and sedimentation properties between cloud water and cloud 
Table 1. Size distribution parameters for non-sulfate aerosols.

\begin{tabular}{lrrr}
\hline Aerosol component & $\mathrm{Ni}^{\mathrm{a}}$ & Mode radius, $\mu \mathrm{m}$ & sigma \\
\hline Fossil fuel OM/BC & 0.428571 & 0.005 & 1.5 \\
& 0.571428 & 0.08 & 1.7 \\
& $1.0 \mathrm{e}-6$ & 2.5 & 1.65 \\
Biomass OM/BC & 0.9987 & 0.0774 & 1.402 \\
and natural OM & $1.306 \mathrm{e}-3$ & 0.3360 & 1.383 \\
& $2.830 \mathrm{e}-3$ & 0.9577 & 1.425 \\
Sea Salt & 0.965 & 0.035 & 1.92 \\
& $3.5 \mathrm{e}-2$ & 0.41 & 1.70 \\
Dust & 0.854240 & 0.05 & 1.65 \\
& 0.145687 & 0.27 & 2.67 \\
& $7.3 \mathrm{e}-5$ & 4.0 & 2.40 \\
\hline
\end{tabular}

${ }^{\mathrm{a}} \mathrm{Ni}$ is the fraction of the total particle number in a given size range and is dimensionless.

ice. Cloud droplet number concentrations were prescribed in the precipitation process and in calculating the radiative properties of clouds. Boville et al. (2006) and Collins et al. (2006a) document the physical parameterizations used in the model and its performance.

The two model components of the coupled system are concurrently run in MPMD (Multiple Processors Multiple Data) mode to exchange aerosol fields and meteorological fields at each advection time step of the IMPACT model. We used 26 vertical levels and a horizontal resolution of $2 \times 2.5$ degrees for both the CAM3 and IMPACT models in this study. The time step for CAM3 was $30 \mathrm{~min}$, and that for advection in IMPACT was $1 \mathrm{~h}$.

\subsection{Nucleation mechanisms}

In the original IMPACT aerosol model (Liu et al., 2005), only BHN using the parameterization of Vehkamäki et al. (2002) was included. As mentioned above, BHN cannot explain the observed nucleation rate in the boundary layer (e.g., Clarke et al., 1998). Moreover, the model study of Lucas and Akimoto (2006) has shown that the simulated nucleation rate from BHN is negligible in the boundary layer. In addition Spracklen et al. (2005a) showed that there was very little change in the simulated MBL aerosol number concentration when BHN was switch off in the lowest $3 \mathrm{~km}$ of their model.

In Wang09, we implemented a parameterization to simulate boundary layer nucleation in the IMPACT model. This parameterization was based on an empirical fit to newly formed particles and their dependence on sulfuric acid vapor from long-term observations of aerosol formation events at Hyytiälä, Finland (Kulmala et al., 2006; Sihto et al., 2006; Riipinen et al., 2007). This parameterization also fits nucleation events measured in a variety of continental and marine atmospheric environments (Kuang et al., 2008). The nucleation rate of $1 \mathrm{~nm}$ particles is first calculated using the param- eterizations from Kulmala et al. (2006) and Sihto et al. (2006) as:

$$
\begin{aligned}
& j_{1 \mathrm{~nm}}=A \times\left[\mathrm{H}_{2} \mathrm{SO}_{4}\right], \\
& \text { or } \\
& j_{1 \mathrm{~nm}}=K \times\left[\mathrm{H}_{2} \mathrm{SO}_{4}\right]^{2},
\end{aligned}
$$

where $\mathrm{A}$ and $\mathrm{K}$ are rate coefficients. In the model, $3 \mathrm{~nm}$ particles are added to the nucleation mode at each time step (which is dynamically determined based on the accuracy of the solution) instead of $1 \mathrm{~nm}$ particles. The rate of formation of $3 \mathrm{~nm}$ particles $\left(j_{3 \mathrm{~nm}}\right)$ is calculated from $j_{1 \mathrm{~nm}}$ using the formula from Kerminen and Kulmala (2002).

For the rate coefficients $\mathrm{A}$ and $\mathrm{K}$, we adopt the median values derived from the case studies in Sihto et al. (2006) which were $1.0 \times 10^{-6} / \mathrm{s}$ and $1.0 \times 10^{-12} \mathrm{~cm}^{3} / \mathrm{s}$, respectively. Wang09 showed that, the inclusion of these boundary layer nucleation mechanisms improved the comparison of simulated aerosol size distributions with observations in the MBL. Furthermore, the use of Eq. (1) and (2) gave similar results, especially in terms of the number concentration of the accumulation mode particles. Here, we choose Eq. (1) to represent boundary layer nucleation. The contribution of BHN and the nucleation mechanism represented by Eq. (1) to the $\mathrm{CCN}$ concentration and to the first aerosol indirect forcing will be quantified.

Although the form of the empirical parameterization for nucleation is generally applicable, variations of several orders of magnitude in the prefactors $\mathrm{A}$ and $\mathrm{K}$ have been observed, depending on location and the environmental conditions (Sihto et al., 2006; Riipinen et al., 2007; Kuang et al., 2008). This indicates that species other than sulfuric acid may play a role in nucleation. For example, biogenic iodine oxides (O' Dowd et al., 2002b), organic species (Zhang et al., 2004), and ammonia (Korhonen et al., 1999) can be important in particle formation. In addition, ion mediated nucleation may be also important (Yu et al., 2008a). Nevertheless, this simple empirical parameterization is still useful for exploring the effects of boundary layer nucleation in global models, given our poor understanding of the mechanisms behind particle formation.

\subsection{Primary-emitted sulfate particles}

Most global model studies that predict both aerosol mass and number have included some fraction of sulfur emissions as primary emitted sulfate particles to represent sub-grid scale nucleation (Liu et al., 2005; Easter et al., 2004; Stier et al., 2005; Adams and Seinfeld, 2002; Spracklen et al. 2005b; Pierce et al., 2007). The amount and size of these particles is chosen to represent the condensational growth and coagulation of both sulfate particles emitted directly from the source and those nucleated shortly after emission (Adams and Seinfeld, 2003). 
Table 2. Hygroscopicity and density for each aerosol component.

\begin{tabular}{lrr}
\hline Aerosol Component & Hygroscopicity $^{\mathrm{a}}$ & Density $\left(\mathrm{g} / \mathrm{cm}^{3}\right)$ \\
\hline Sulfate & 0.51 & 1.7 \\
BC & $5.0 \mathrm{e}-7$ & 1.5 \\
OM & 0.13 & 1.2 \\
Sea Salt & 1.16 & 2.2 \\
Dust & 0.14 & 2.6 \\
\hline
\end{tabular}

${ }^{\mathrm{a}}$ The hygroscopicity parameter depends on the number of dissolved ions per molecule, the osmotic coefficient, the soluble mass fraction, the component density, and the molecular weight, as defined by Eq. (3) in Abdul-Razzak and Ghan (2000), and values are taken from Ghan et al. (2001b).

In the IMPACT aerosol model (Liu et al., 2005), $2 \%$ of anthropogenic sulfur was assumed to be emitted as primary sulfate particles, with $85 \%$ of the mass in the accumulation mode with a mode diameter of $70 \mathrm{~nm}$ and a geometric standard deviation of 2.0 , and the remaining $15 \%$ of the mass in the Aitken mode with a mode diameter of $10 \mathrm{~nm}$ and a geometric standard deviation of 1.6. Wang09 showed that, this primary-emitted sulfate has a large impact on the simulated aerosol number concentrations, consistent with the results from Adams and Seinfeld (2002) and Spracklen et al. (2005b). In this study, we will further examine how these primary-emitted sulfate particles affect the CCN number concentration and the 1 st indirect forcing.

2.4 Calculation of cloud droplet number and the 1 st indirect forcing

We used a procedure similar to that used by Chen and Penner (2005) to calculate the aerosol indirect forcing (Fig. 1). First, the aerosol fields calculated from the coupled model are used to calculate the cloud droplet number concentration using the cloud droplet activation parameterization of AbdulRazzak and Ghan (2000, 2002). Then, the droplet number concentration is used to calculate the cloud droplet effective radius (Rotstayn and Liu, 2003). Finally, the cloud droplet effective radius is used to calculate the cloud optical depth and the first aerosol indirect forcing using an offline radiative transfer model taken from the NCAR CAM3. Detailed descriptions of each step follow.

The cloud droplet number concentration was calculated from the aerosol fields using a parameterization based on Köhler theory (Abdul-Razzak and Ghan, 2000, 2002). This parameterization combines the treatment of multiple aerosol types and a sectional representation of size to deal with arbitrary aerosol mixing states and arbitrary aerosol size distributions. Five categories of aerosols are externally mixed: pure sulfate, biomass burning $\mathrm{OM} / \mathrm{BC}$ coated with sulfate, fossil fuel OM/BC coated with sulfate, sea salt with sulfate, and dust coated with sulfate; coating by sulfate is treated

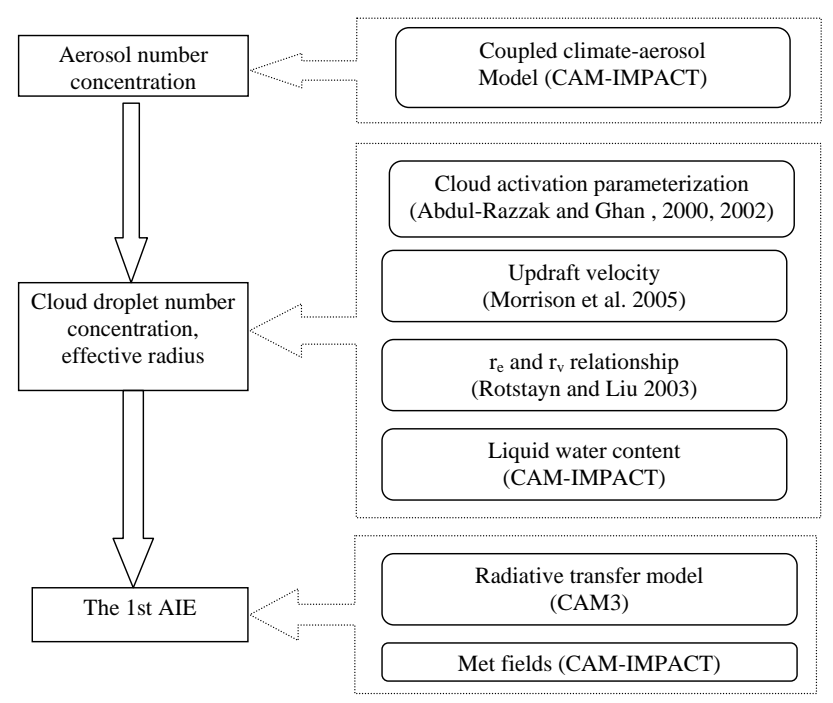

Fig. 1. Diagram showing the processes included in the estimation of the first aerosol indirect effect.

as internally mixed in each aerosol type. The bulk hygroscopicity parameter for each category of aerosol is the volume-weighted average of the parameters for each component taken from Ghan et al. (2001b) (see Table 2). The size distributions for pure sulfate, which have spatial and temporal variations, are predicted from the coupled CAMIMPACT model, while the size distributions of the nonsulfate aerosols are prescribed as in Table 1. In applying the Abdul-Razzak and Ghan parameterization, the size spectrum for each aerosol category is divided into 30 bins.

The vertical velocity used in the cloud activation parameterization is calculated from

$w=\bar{w}+c \times \sigma_{w}$,

(Lohmann et al., 1999, 2007; Takemura et al., 2005; Jiang and Cotton, 2005), where $\bar{w}$ is the large-scale vertical velocity, $\sigma_{w}$ is the subgrid-scale variance of the vertical velocity, and $c$ is a coefficient. This formula takes the non-linear dependence of the cloud droplet number on the vertical velocity into account. $\sigma_{w}$ is diagnosed (Morrison et al., 2005) from

$\sigma_{w}=K / m_{l}$

where $K$ is the eddy diffusivity from the CAM3 model and $m_{l}$ is the mixing length. The mixing length is calculated based on Holtslag and Boville (1993) from the altitude $\mathrm{z}$ and the asymptotic scale length $\lambda_{c}(\mathrm{~m})$, which is diagnosed from the following formula:

$\lambda_{c}=300 \mathrm{~m}$ for $z \leq z_{\mathrm{pbl}}$,

and

$\lambda_{c}=30+270 \exp \left(-z / z_{\mathrm{pbl}}\right)$ for $z \geq z_{\mathrm{pbl}}$, 
Table 3. Description of cases.

\begin{tabular}{llll}
\hline Case name & Within BL $^{\mathrm{a}}$ & Within FT $^{\mathrm{b}}$ & Primary sulfate \\
\hline BHN & $\mathrm{BHN}^{\mathrm{c}}$ & BHN & $0 \% \mathrm{SO}_{2}^{\mathrm{d}}$ \\
EMP & $\mathrm{EMP}$ & No FT nucleation & $0 \% \mathrm{SO}_{2}$ \\
BLBHN & BHN & No FT nucleation & $0 \% \mathrm{SO}_{2}$ \\
BHN_PRIM & BHN & BHN & $2 \% \mathrm{SO}_{2}^{\mathrm{f}}$ \\
BHN_EMP & EMP & BHN & $0 \% \mathrm{SO}_{2}$ \\
BHN_EMP_PRIM & EMP & BHN & $2 \% \mathrm{SO}_{2}$ \\
\hline
\end{tabular}

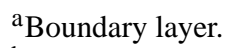

${ }^{\mathrm{b}}$ Free troposphere.

${ }^{\mathrm{c}}$ Binary homogeneous nucleation (scheme of Vehkamäki et al., 2002).

${ }^{\mathrm{d}} 0 \%$ of anthropogenic $\mathrm{SO}_{2}$ emissions are input as primary sulfate.

${ }^{\mathrm{e}}$ The empirical parameterization for boundary layer nucleation from Eq. (1).

$\mathrm{f}_{2} \%$ of anthropogenic $\mathrm{SO}_{2}$ emissions are input as primary sulfate.

where $z_{\mathrm{pbl}}$ is the height of the planetary boundary layer. The minimum value of $\sigma_{w}$ is set to $0.1 \mathrm{~m} / \mathrm{s}$, following Ghan et al. (1997) and Morrison et al. (2005).

In Lohmann et al. (1999, 2007) and Takemura et al. (2005), fixed values for $c$ are used (0.7 in Lohmann et al., 1999 and Takemura et al., 2005; 1.3 in Lohmann et al., 2007). Jiang and Cotton (2005) diagnosed $c$ to be 0.24 using large-eddy simulations of six observed boundary layer cases, but also showed that the value of $c$ diagnosed from these simulations varied from small values for cumulus clouds (around $0.10)$ to two to five times larger for stratocumulus clouds (0.30-0.55) (Table 1 in Jiang and Cotton, 2005), which implies that the value of $c$ may depend on other parameters, such as $\sigma_{w}$ or $\bar{w}$. We diagnosed $c$ by calculating cloud droplet number concentration and integrating over a normal vertical velocity distribution with a mean of zero and a standard deviation of $\sigma_{w}$ and setting the computed droplet number to that obtained using Eq. (3). Our results show that the coefficient $c$ in Eq. (3) must be treated as a function of the variance of the vertical velocity, in order to reproduce the results from the normal probability distribution and that it should decrease for larger values of $\sigma_{w}$. Based on our tests, we used the following empirical formula for $c$ in our droplet nucleation parameterization:

$c=0.20$, when $\sigma_{w}>10 \mathrm{~m} \mathrm{~s}^{-1}$

$c=\frac{\log \sigma_{w}-\log 0.1}{\log 10-\log 0.1} \times 0.6+\frac{\log 10-\log \sigma_{w}}{\log 10-\log 0.1} \times 0.1$,

when $0.1 \mathrm{~m} \mathrm{~s}^{-1}<\sigma_{w}<10 \mathrm{~m} \mathrm{~s}^{-1}$

$c=0.60$, when $\sigma_{w}<0.1 \mathrm{~m} \mathrm{~s}^{-1}$
The coefficient $c$ should also depend on the mean velocity and the number concentration of accumulation mode aerosol (radius $>50 \mathrm{~nm}$ ). But, since the large scale vertical velocity in a grid of the GCM is normally less than $0.05 \mathrm{~m} / \mathrm{s}$, we neglect the dependence of $c$ on the mean velocity as an approximation. Moreover, as long as the accumulation mode aerosol concentration is less than $1000 / \mathrm{cm}^{3}$, the cloud droplet number concentration calculated from this approximation is within $10 \%$ of that calculated by integrating over the normal vertical velocity distribution.

In part, because we suspect that our sea salt concentrations are underpredicted (Wang09), we set a lower limit to the cloud droplet number concentration of $20 \mathrm{~cm}^{-3}$ to represent the minimum cloud droplet concentration in the background atmosphere. As we show in Sect. 6, however, the use of this minimum number concentration adds uncertainties to the calculated 1st AIE.

The volume mean radius of the cloud droplets is calculated from the cloud drop number concentration and the liquid water content of the cloud. Then the cloud droplet effective radius is parameterized based on Rotstayn and Liu (2003), which takes account of the change in the dispersion of the cloud droplet size distribution due to the change in the cloud droplet number. The middle curve in Fig. 1 from Rotstayn and Liu (2003) is used in this study.

The radiative transfer model is that of the NCAR CAM3 (Collins et al., 2006a), and the meteorological fields are taken from the output of the coupled CAM3/IMPACT model with a frequency of every four hours. The time step for the radiative transfer model is one hour. The concentrations of the trace gases $\mathrm{CO}_{2}, \mathrm{O}_{3}$ are the same as those in the NCAR CAM3 model. We apply the effects of aerosols on clouds to all liquid clouds, and to both large scale and convective clouds. The sensitivity of the 1st AIE to cloud types included in the calculation is discussed in Sect. 6.

\subsection{Overview of the model experiments}

Table 3 lists all of the cases considered here. In case BHN, only binary homogeneous nucleation is included in both the boundary layer (BL) and the FT, and no primary-emitted sulfate particles are included. In case EMP, only the empirical boundary layer nucleation from Eq. (1) is included. There is no nucleation in the FT or any primary-emitted particulate sulfate. BLBHN is the same as EMP, except that binary homogeneous nucleation replaces the nucleation parameterization based on Eq. (1) in the boundary layer. BHN_PRIM is the same as BHN except that $2 \%$ of the anthropogenic sulfur emissions are emitted as sulfate particles. BHN_EMP is the same as BHN except that the boundary layer nucleation scheme from Eq. (1) replaces binary homogeneous nucleation in the boundary layer. Finally, BHN_EMP_PRIM is the same as BHN_EMP except that $2 \%$ of the anthropogenic sulfur emissions are emitted as sulfate particles. BHN, BHN_PRIM, BHN_EMP, and BHN_EMP_PRIM were 
compared with observations in Wang09. The EMP and BLBHN cases are added here to quantify the effect of BHN in the FT on CCN concentrations and the AIE.

The role of nucleation in the boundary layer on $\mathrm{CCN}$ concentrations can be quantified by comparing BHN_EMP with BHN and BHN_EMP_PRIM with BHN_PRIM. The role of nucleation in the FT can be quantified by comparing BHN with BLBHN and BHN_EMP with EMP. Finally, the role of representing nucleation in the boundary layer by primary-emitted sulfate particles can be quantified by comparing BHN_PRIM with BHN and BHN_EMP_PRIM with BHN_EMP.

We ran two simulations for each of the cases in Table 3: one with the present day (PD) emissions and one with the preindustrial emissions (PI). In each simulation, the coupled model was integrated for 1 year after an initial spin-up of four months. Since the aerosol fields are not allowed to change heating rates or droplet number concentrations in the climate model, the aerosol fields do not affect the simulated meteorological fields, which allows us to compare the aerosol fields from different cases from one-year simulations, as in Wang09. Then the resulting aerosol fields from the coupled model are used to calculate cloud droplet number concentration and 1st indirect forcing, following the procedure described in Sect. 2.4.

\section{Global aerosol mass budgets in PD and PI simulations}

Anthropogenic sulfur emissions were from Smith et al. $(2001,2004)$, and those for the year $2000(61.3 \mathrm{Tg} \mathrm{S}$ per year) and the year 1850 (1.51 $\mathrm{Tg} \mathrm{S}$ per year) were used for the present day (PD) and the preindustrial (PI) simulations, respectively. Anthropogenic emissions of fossil fuel and biomass burning carbonaceous aerosols were from Ito and Penner (2005) but adjusted as discussed in Wang09. The year 2000 PD emissions include fossil fuel BC and OM (5.8 $\mathrm{Tg} \mathrm{BC}$ and $15.8 \mathrm{Tg} \mathrm{OM}$ per year), and biomass burning $\mathrm{BC}$ and $\mathrm{OM}(4.7 \mathrm{Tg} \mathrm{BC}$ and $47.4 \mathrm{Tg} \mathrm{OM}$ per year). PI emissions were those for 1870 (23.0 Tg per year for OM and $2.52 \mathrm{Tg}$ per year for $\mathrm{BC}$ ). Natural emissions included volcanic $\mathrm{SO}_{2}$ (4.79 $\mathrm{Tg} \mathrm{S}$ per year from Andres and Kasgnoc, 1998), marine dimethyl sulfide (DMS) (26.1 Tg S per year from Kettle and Andreae, 2000), OM from vegetation (14.5 Tg per year from Penner et al., 2001), and mineral dust provided by Ginoux (private communication, 2004) for the year 1998 based on the algorithm of Ginoux et al. (2001) and were the same for both the PD and PI simulations. Sea salt emissions (around $2560 \mathrm{Tg}$ per yr) were calculated online in the coupled CAM/IMPACT model using the method defined in Gong et al. (1997).

The global aerosol mass budgets for all six cases are very similar, and only the results in the BHN_PRIM case are shown in Table 4. Aerosol burdens for the present day simulations are within the range of aerosol burdens simulated by other models (Wang09). The difference between the present day and preindustrial simulations is largely determined by the difference in the emissions, including both their amount and location. The difference is also affected by, but to a lesser extent, the difference in the scavenging efficiencies for the initially hydrophobic species, such as black carbon, organic carbon, and dust. For example, even though the emissions of mineral dust are the same in both the PD and PI simulations, the burden is slightly smaller in the PD simulation resulting from the larger wet scavenging efficiency of dust coated with sulfate.

\section{Present day CCN concentration}

Present day zonal annual-average $\mathrm{CCN}$ concentrations at $0.2 \%$ supersaturation and present day annual-average $\mathrm{CCN}$ concentrations at the 3rd model level (around $930 \mathrm{hPa}$, representing the boundary layer) are shown in Fig. 2 and Fig. 3, respectively, while Fig. 4 shows the ratio of the present day annual-average boundary layer $\mathrm{CCN}$ concentration between different cases. As expected, the BLBHN case produces the smallest CCN concentrations and the BHN_EMP_PRIM case produces the largest concentrations. Thus, binary homogeneous nucleation is generally not very effective in the boundary layer, whereas the introduction of primary aerosols together with the boundary layer nucleation scheme both act to increase $\mathrm{CCN}$ concentrations in the boundary layer over those from just BHN.

The effects of including the empirical boundary layer nucleation scheme can be quantified by comparing simulations with and without this nucleation mechanism. These effects are large when no primary sulfate particles are emitted, and the global average $\mathrm{CCN}$ concentration in the boundary layer is enhanced by $31.4 \%$ (Fig. $4 \mathrm{a}$ and Table 5). In the MBL, boundary layer nucleation increases $\mathrm{CCN}$ concentrations by more than 30\% (compare Fig. 3b and e, and Fig. 4a). In particular, CCN concentrations are increased by $75 \%$ to more than $150 \%$ over the tropical Eastern Pacific and in the middle latitudes of North America and Europe and over the North Atlantic. Over these regions, the production of sulfuric acid gas is high and the concentration of primary particles is low, which favors the occurrence of nucleation events. Over continental regions without high sulfuric acid concentrations, the increases in CCN concentrations are small (less than 10\%). The effects of the empirical boundary layer nucleation mechanism are also small at high latitudes because of the lower sulfuric acid gas concentration.

In contrast, in the cases where $2 \%$ of the anthropogenic $\mathrm{SO}_{2}$ emissions is emitted as particulate sulfate (BHN_EMP_PRIM vs. BHN_PRIM), the effects of the empirical boundary layer nucleation are much smaller and only increase global average $\mathrm{CCN}$ concentration in the boundary layer by $5.3 \%$ (Fig. $4 \mathrm{~b}$ and Table 5). The increases in CCN concentrations over most oceanic regions in the Northern 
Table 4. Aerosol emissions and burdens in the present day and preindustrial simulations for the BHN_PRIM case.

\begin{tabular}{lllll}
\hline \multirow{2}{*}{ Aerosol types } & \multicolumn{3}{l}{ Sources $(\mathrm{Tg} / \mathrm{yr}$ or Tg S/yr) } & \multicolumn{2}{l}{ Burden (Tg or Tg S) } \\
& PD & PI & PD & PI \\
\hline Sulfate & 60.06 & 24.00 & 0.86 & 0.33 \\
Black carbon & 10.51 & 2.52 & 0.13 & 0.033 \\
Organic carbon & 77.52 & 37.44 & 1.02 & 0.47 \\
Dust size $^{\mathrm{a}}(\mu \mathrm{m})$ & & & & \\
$0.05-0.63$ & 76.57 & 76.57 & 1.62 & 1.62 \\
$0.63-1.25$ & 291.53 & 291.53 & 6.03 & 6.40 \\
$1.25-2.50$ & 662.58 & 662.58 & 10.83 & 11.00 \\
$2.50-10.0$ & 1325.17 & 1325.17 & 4.28 & 4.30 \\
$0.05-10.0$ & 2355.86 & 2355.86 & 22.77 & 23.34 \\
Sea Salt size ${ }^{\mathrm{a}}(\mu \mathrm{m})$ & & & & \\
$0.05-0.63$ & 112.47 & 112.86 & 0.42 & 0.42 \\
$0.63-1.25$ & 430.90 & 432.34 & 1.56 & 1.56 \\
$1.25-2.50$ & 932.15 & 935.21 & 2.56 & 2.57 \\
$2.50-10.0$ & 1079.04 & 1082.65 & 0.46 & 0.47 \\
$0.05-10.0$ & 2554.57 & 2563.07 & 5.01 & 5.02 \\
\hline
\end{tabular}

a radius.

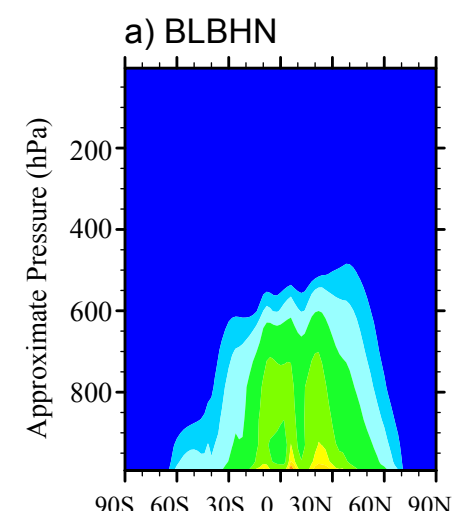

$90 \mathrm{~S} 60 \mathrm{~S} 30 \mathrm{~S} \quad 0 \quad 30 \mathrm{~N} 60 \mathrm{~N} 90 \mathrm{~N}$

d) EMP

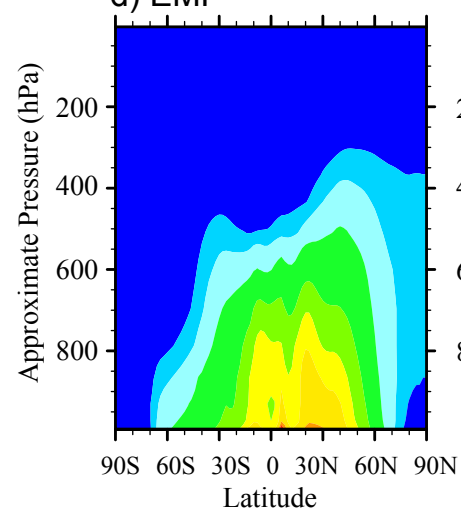

b) $\mathrm{BHN}$

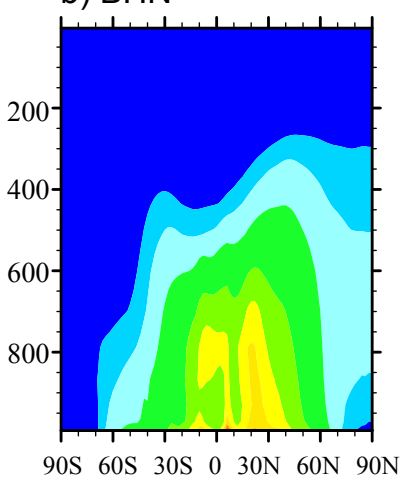

e) BHN_EMP

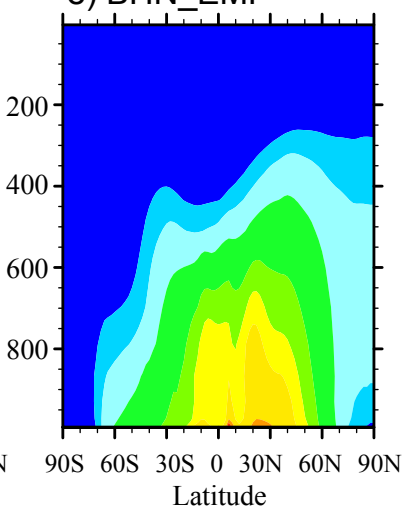

c) BHN_PRIM
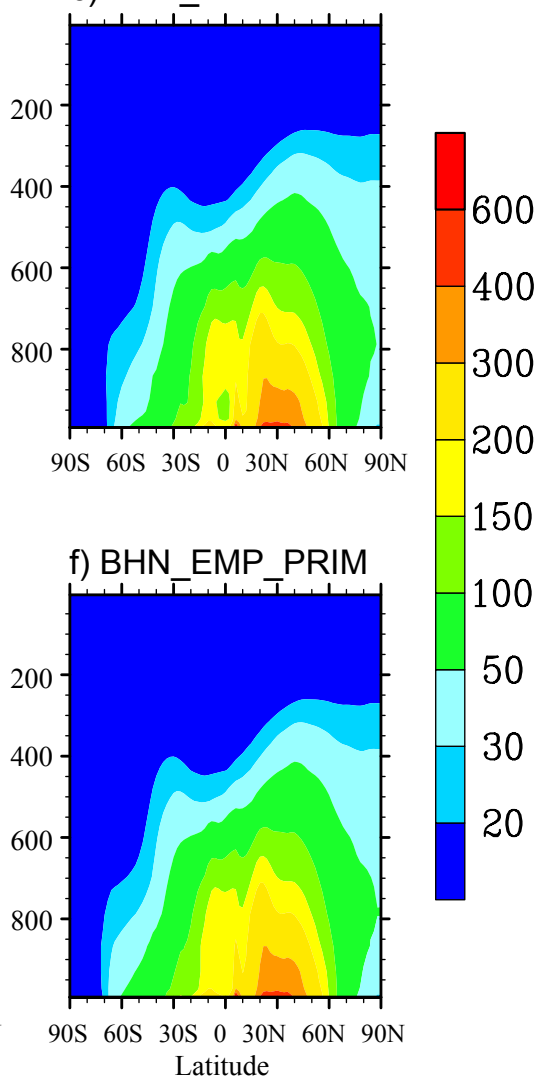

Fig. 2. Present day zonal annual-average $\mathrm{CCN}$ concentrations $\left(\mathrm{cm}^{-3}\right)$ at $0.2 \%$ supersaturation for all six cases. CAM3 used a hybrid vertical coordinate and the pressure at the $k$ th model level is given by $p(k)=A(k) p_{0}+B(k) p_{s}$, where $p_{s}$ is surface pressure, $\mathrm{p}_{0}$ is a specified constant pressure $(1000 \mathrm{hPa}), \mathrm{A}$ and B are coefficients. Data are plotted as a function of this hybrid vertical coordinate times 1000 and labeled "Approximate Pressure". 

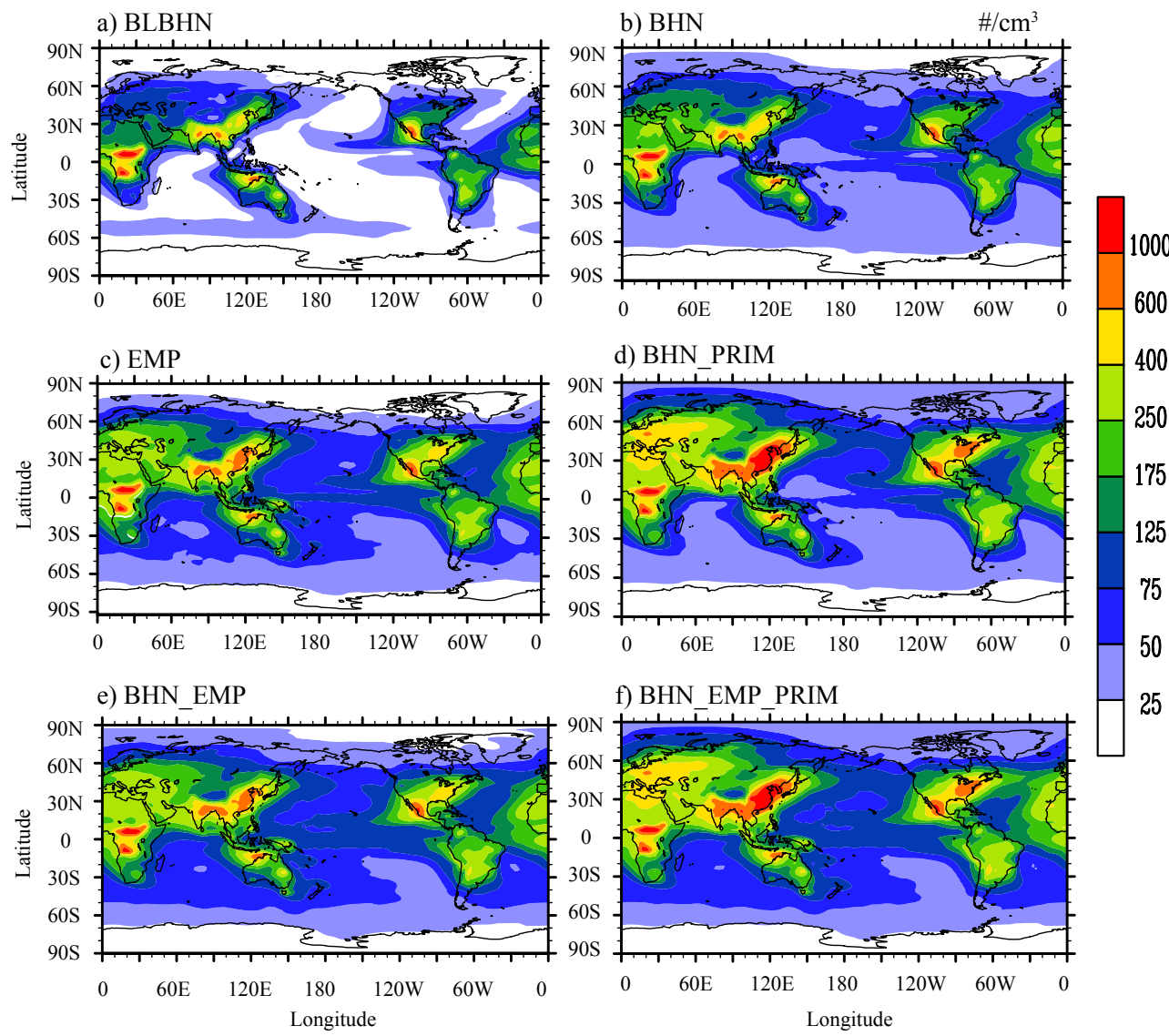

Fig. 3. Present day annual-average $\mathrm{CCN}$ concentrations $\left(\mathrm{cm}^{-3}\right)$ at $0.2 \%$ supersaturation near $930 \mathrm{hPa}$ (the third model level) for all six cases.

Table 5. Global annual-averaged CCN concentration in the boundary layer in the PD simulation, cloud top effective radius in the PD simulation, change in the cloud top effective radius from anthropogenic emissions, anthropogenic fraction of $\mathrm{CCN}$ in the boundary layer, column-integrated anthropogenic fraction of $\mathrm{CCN}$, and the 1st AIE for all six cases.

\begin{tabular}{lrccccc}
\hline Case name & $\mathrm{CCN}$ in the BL in PD $\left(\# / \mathrm{cm}^{3}\right)$ & Reff $^{\mathrm{a}}$ in PD $(\mu \mathrm{m})$ & Change in Reff $(\mu \mathrm{m})$ & $\mathrm{f}_{\mathrm{accn}}^{\mathrm{b}}$ in the BL & Column-integrated $\mathrm{f}_{\mathrm{accn}}$ & 1 st AIE $\left(\mathrm{w} / \mathrm{m}^{2}\right)$ \\
\hline BLBHN & 70.34 & 13.50 & -0.69 & 46.32 & $48.60 \%$ & -0.81 \\
BHN & 104.24 & 12.24 & -0.86 & 43.88 & $48.76 \%$ & -1.55 \\
EMP & 128.37 & 11.83 & -0.84 & 46.77 & $49.36 \%$ & -1.22 \\
BHN_PRIM & 159.89 & 11.77 & -1.23 & 62.07 & $57.57 \%$ & -2.03 \\
BHN_EMP & 136.92 & 11.61 & -0.84 & 46.37 & $50.62 \%$ & -1.49 \\
BHN_EMP_PRIM & 168.77 & 11.46 & -0.97 & 46.09 & $55.36 \%$ \\
\hline
\end{tabular}

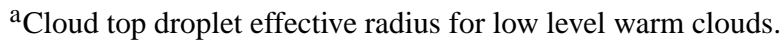

${ }^{\mathrm{b}} \mathrm{PD}$ Anthropogenic fraction of CCN concentrations.

Hemisphere $(\mathrm{NH})$ and over land areas in both hemispheres are less than 10\% (compare Fig. 3d and $\mathrm{f}$ and Fig. 4b). The inclusion of the empirical boundary layer nucleation scheme can even lead to a decrease in the CCN number concentrations over some regions, such as western United States, as also shown in Spracklen et al. (2008). This is because the addition of tiny particles from boundary layer nucleation events slows the growth of particles into $\mathrm{CCN}$-sized particles by competing with larger particles for the condensation of sul- furic acid gas. In the MBL over the tropical Pacific and in the $\mathrm{SH}$, the effects of including the empirical boundary layer nucleation mechanism are still large since the emissions of anthropogenic primary sulfate particles are much smaller over these regions.

Spracklen et al. (2008) used the empirical nucleation rate represented by Eq. (1) but with different rate coefficients to study the effects of the boundary layer nucleation on CCN concentrations in spring (March-May) and how these depend 
a) BHN_EMP / BHN

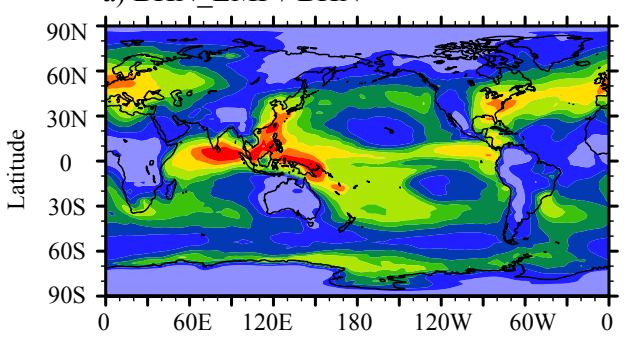

c) $\mathrm{BHN} / \mathrm{BLBHN}$

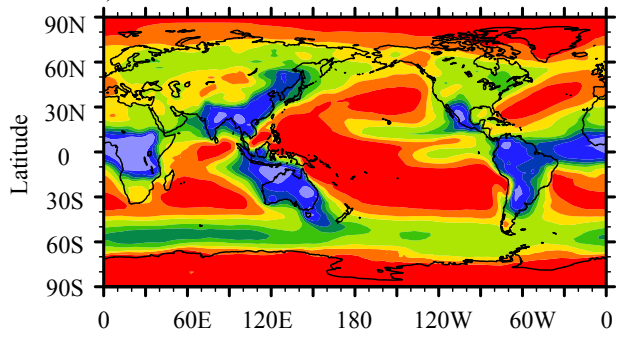

e) BHN_PRIM / BHN

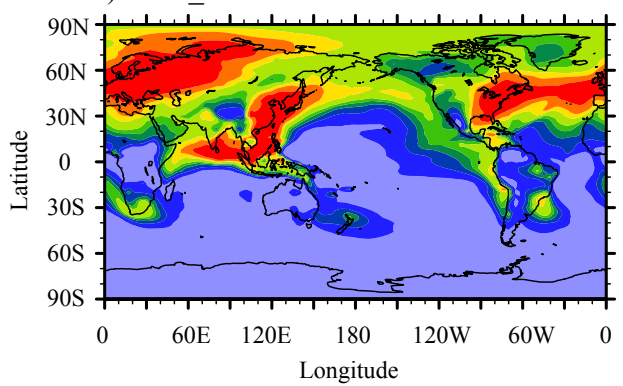

b) BHN_EMP_PRIM/BHN_EMP

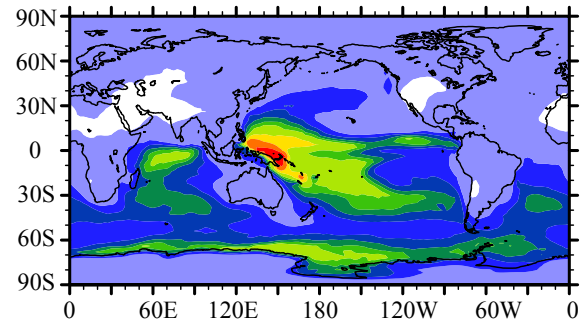

d) BHN_EMP/EMP

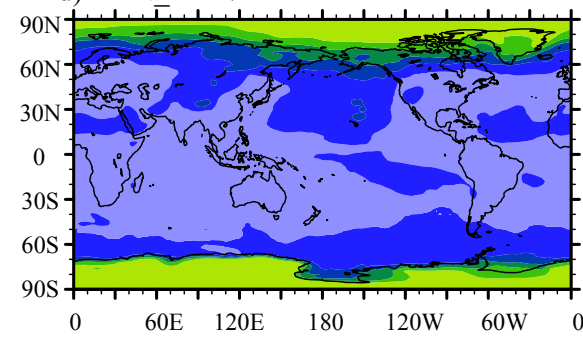

f) BHN_EMP_PRIM / BHN_EMP

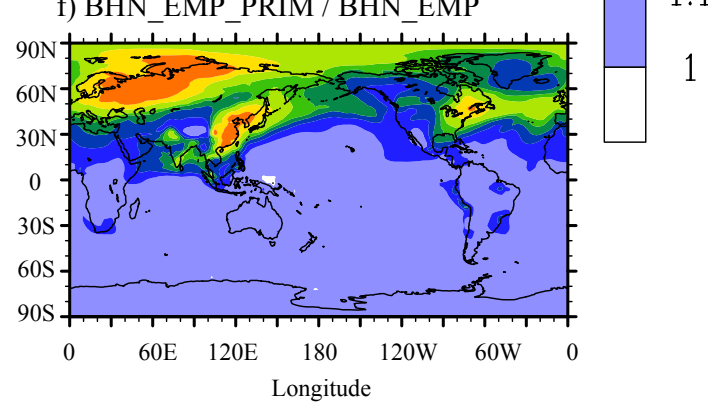

2.5

2

1.75

1.5

1.4

1.3

1.2

1.1

1

Fig. 4. Ratio of present day annual-average CCN concentrations (at $0.2 \%$ supersaturation) near $930 \mathrm{hPa}$ (the third model level) between different cases.

on rate coefficient. In their model, $2.5 \%$ of the anthropogenic $\mathrm{SO}_{2}$ emissions were emitted as primary sulfate with the aged size distribution that was suggested for the AEROCOM emissions inventory (personal communication, D. Spracklen; Dentener et al., 2006). The majority (88\%) of the primary anthropogenic $\mathrm{SO}_{2}$ comes from the industrial sector and is emitted at a diameter of $1 \mu \mathrm{m}$, while the remaining fraction comes from the traffic sector and is emitted at a diameter of $30 \mathrm{~nm}$. Spracklen et al. (2008) showed that the enhancement in April is $9 \%$ when the rate coefficient is $2.0 \times 10^{-6} / \mathrm{s}$. Their result is close to our annual average result $(5.3 \%$ enhancement in the case when primary-emitted sulfate particles are included), although we have somewhat different emissions and concentrations of other primary particles (e.g., carbonaceous aerosol, sea salt) and have a different magnitude of emissions of the precursor species ( $\mathrm{SO}_{2}$ and DMS) of sulfuric acid gas. They also showed that the enhancement in April ranges from 3 to $20 \%$ when the rate coefficient ranges from $2.0 \times 10^{-8}$ to $2.0 \times 10^{-4} / \mathrm{s}$.
Our results suggest that the effects of including boundary layer nucleation on the CCN concentrations depend on both the rate coefficients (as shown by Spracklen et al., 2008), and in an important way on the assumed and simulated primary particles. When primary-emitted sulfate particles are included, the effect of including boundary layer nucleation is much smaller because the depletion of sulfuric acid gas from the condensational growth of primary particles decreases the frequency and intensity of nucleation events, and slows the growth of freshly nucleated particles. Although only primary particles from anthropogenic sulfate are examined here, we would expect that the effects of boundary layer nucleation on $\mathrm{CCN}$ concentrations also depends on the treatment of other primary particles (carbonaceous aerosols, dust and sea salt). Given the large uncertainties in the treatment of these other primary particles in global aerosol models, the accurate determination of the effects of boundary layer nucleation on $\mathrm{CCN}$ concentrations may require significantly improved estimates of emissions. 
a) BLBHN
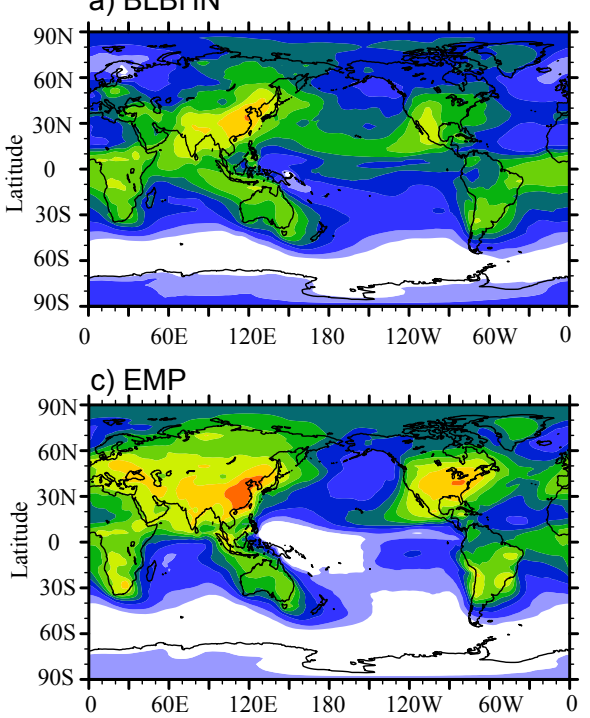

e) BHN_EMP

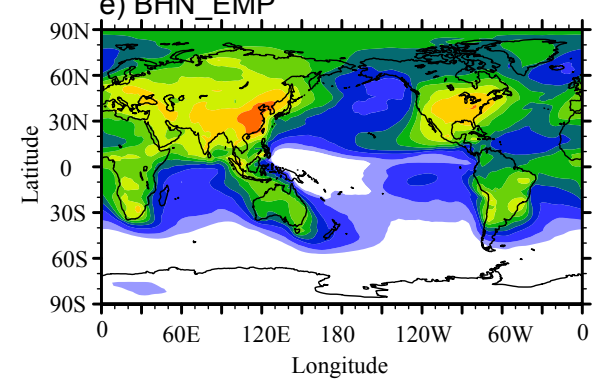

b) $\mathrm{BHN}$
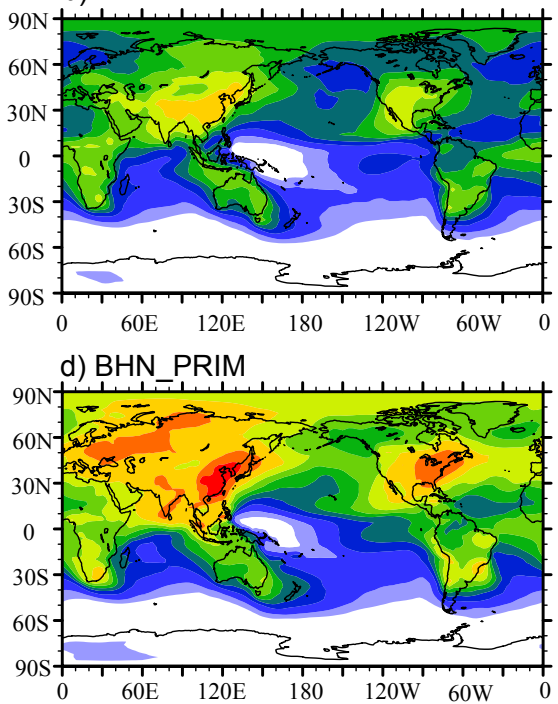

f) BHN_EMP_PRIM

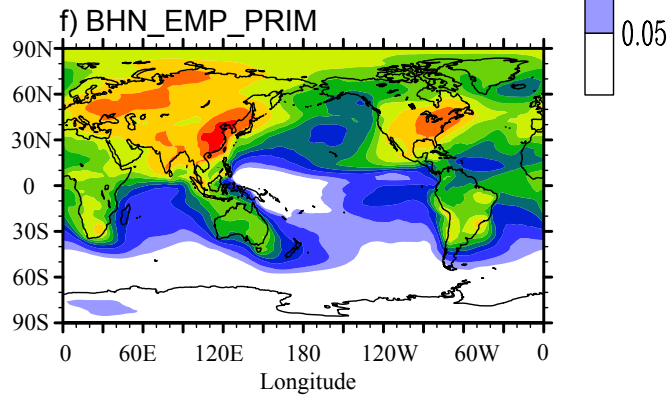

Fig. 5. Annual-average anthropogenic fraction of CCN concentration at $0.2 \%$ supersaturation near $930 \mathrm{hPa}$ (the third model level) for all six cases.

The effect of mixing free tropospheric aerosols into the boundary layer can be quantified by comparing cases in which binary homogeneous nucleation takes place throughout the atmosphere (case BHN or BHN_EMP) with those in which nucleation only takes place within the boundary layer (case BLBHN or EMP). Figure $4 \mathrm{c}$ shows that if only binary homogeneous nucleation is considered (BHN vs. BLBHN), the mixing of aerosols from the FT into the boundary layer has a large impact on the simulated CCN concentrations in the boundary layer. The small concentrations of $\mathrm{CCN}$ particles produced within the boundary layer in this case allows particles to diffuse into the boundary layer from above causing higher concentrations there, especially in the MBL over regions where primary particles have little influence on the $\mathrm{CCN}$ concentrations. In these regions concentrations are increased by more than $200 \%$ (compare Fig. $3 a$ and b and Fig. 4c). These results are consistent with the model study by Spracklen et al. (2005a). They are also consistent with the analysis of Clarke et al. (2006), who estimated that entrainment from the FT can provide $35 \%-80 \%$ of the $\mathrm{CCN}$ flux into the MBL over regions between $40^{\circ} \mathrm{S}$ and $40^{\circ} \mathrm{N}$.
In the case where the empirical boundary layer nucleation scheme is included (BHN_EMP vs. EMP), nucleation in the free troposphere increases boundary layer particles by less than $20 \%$ everywhere except near the poles (Fig. 4d). This shows that, if boundary layer nucleation events happen as frequently as Eq. (1) suggests, the entrainment from the free troposphere into the boundary layer is not as important as previously thought. The effects of BHN in the FT are most important at high latitudes and in the middle troposphere, (Fig. 4d and compare Fig. 2d and e) because the impact of the boundary layer nucleation is small in these regions (compare Fig. $2 b$ and e).

The inclusion of primary-emitted sulfate particles significantly increases CCN concentrations (Fig. $4 \mathrm{e}$ and f). In the scenarios where the empirical boundary layer nucleation scheme is not included (BHN vs. BHN_PRIM), the inclusion of primary-emitted particulate sulfate increases $\mathrm{CCN}$ number concentrations in both the boundary layer and free troposphere, but the main effects are limited to the NH (compare Fig. $2 b$ and c, see Fig. 4e). Over regions strongly influenced by industrial pollution, $\mathrm{CCN}$ concentrations are increased by 
a) BLBHN

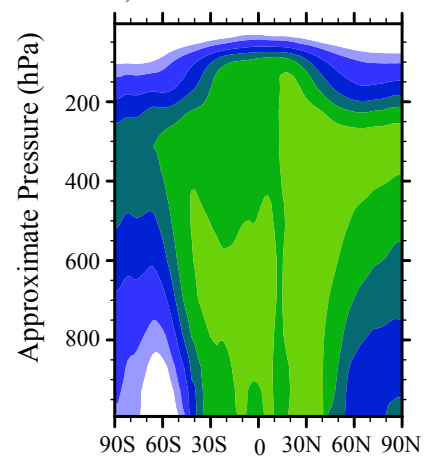

d) EMP

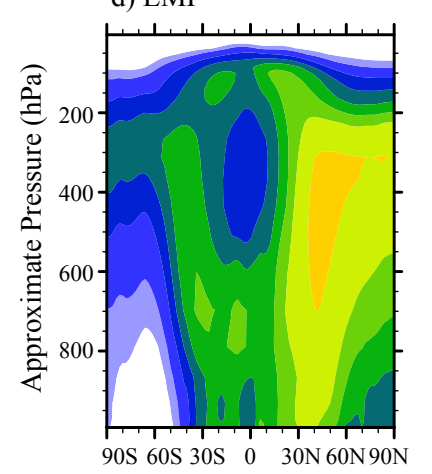

b) BHN

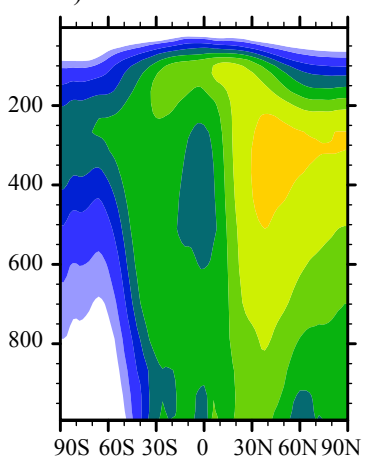

e) BHN_EMP

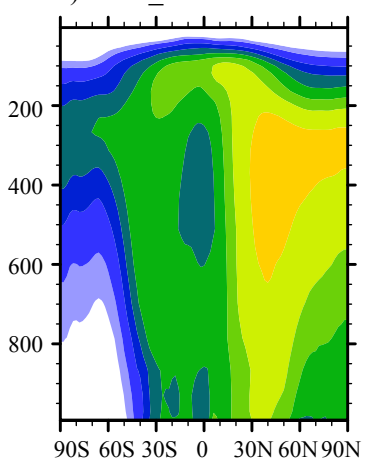

c) BHN PRIM

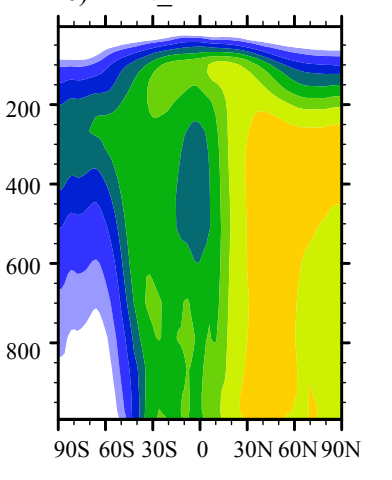

0.9

0.8

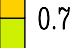

0.6

0.5

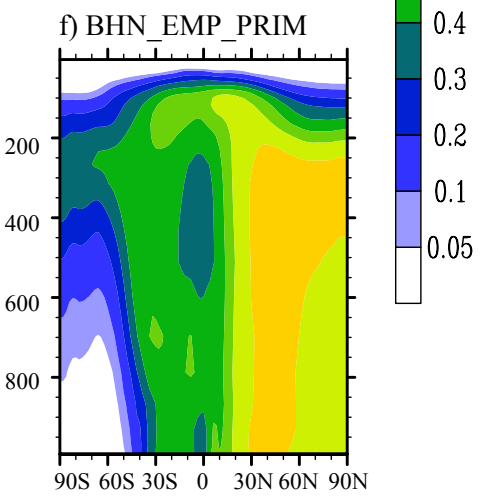

Fig. 6. Present day zonal annual-average anthropogenic fraction of $\mathrm{CCN}$ concentration at $0.2 \%$ supersaturation. "Approximate pressure" is defined in the caption to Fig. 2.

more than $200 \%$, which is consistent with the results from previous studies (Adams and Seinfeld, 2002; Spracklen et al., 2005b). In the cases where the boundary layer nucleation scheme is included (BHN_EMP_PRIM vs. BHN_EMP), the effects of primary-emitted particles are smaller than when it is not (compare Fig. 4e and f) which is due to the competition for sulfuric acid gas between nucleation of new particles and condensation onto pre-existing particles. The decreases in the frequency and intensity of boundary layer nucleation partly offset the increase in the aerosol particles from the primary-emitted sulfate particles.

\section{Anthropogenic contribution to $\mathrm{CCN}$ concentrations}

It is important to understant the perturbation to the $\mathrm{CCN}$ concentrations between the PD and PI simulations in order to understand variations in the aerosol indirect forcing. Figures 5 and 6 show the annual-average boundary layer (third model level) and the zonal mean PD anthropogenic fraction of $\mathrm{CCN}$ concentrations, respectively. The PD anthropogenic fraction of $\mathrm{CCN}$ concentrations is calculated as the increase in the $\mathrm{CCN}$ concentrations from the PI to the PD divided by the $\mathrm{CCN}$ concentrations in the PD. In the BHN_PRIM case, present day anthropogenic emissions contribute $62 \%$ of the
CCN concentrations in the boundary layer $(\sim 930 \mathrm{hPa})$. This fraction is comparable with that reported by Spracklen et al. (2005a) (59\% in December and 61\% in July at the surface) in a model that only included sulfate and sea salt aerosols, and with that reported by Adams and Seinfeld (2002) (60\%) in a model that only included sulfate aerosols. Our results show that over polluted regions, such as East Asia, the eastern United States and Europe, anthropogenic emissions contribute more than $80 \%$ of the $\mathrm{CCN}$, but over remote oceanic regions the contribution from anthropogenic emissions is much smaller (Fig. 5d). For example, anthropogenic emissions contribute less than $5 \%$ of $\mathrm{CCN}$ in the SH south of $50^{\circ} \mathrm{S}$.

There is a large difference in the contribution of $\mathrm{CCN}$ from anthropogenic emissions to the zonal mean $\mathrm{CCN}$ concentration between the $\mathrm{NH}$ and $\mathrm{SH}$. In the $\mathrm{NH}$ middle latitudes, the anthropogenic fraction of CCN is of order $\approx 60-80 \%$ in Fig. $6 \mathrm{c}, \mathrm{d}$, e, and $\mathrm{f}$ from the surface to the upper troposphere $(200 \mathrm{hPa})$. The simulations with the largest values near surface are those that have primary-emitted sulfate particles (compare, for example, Fig. 6b and c), and the simulations with the largest values in the upper troposphere are those that either have BHN in the FT or have the empirical boundary layer mechanism in the BL (compare Fig. $6 \mathrm{~b}$ and $d$ with a). 
It is interesting that the empirical boundary layer mechanism increases the anthropogenic fraction of $\mathrm{CCN}$ more in the upper troposphere than it does at the surface (Fig. 6d) over the $\mathrm{NH}$. This is because pure sulfate particles have a larger contribution to the anthropogenic fraction of $\mathrm{CCN}$ concentrations in the upper troposphere than in the lower troposphere in the NH (Fig. 2a and d). In the SH middle and high latitudes, the anthropogenic fraction of $\mathrm{CCN}$ is small near the surface (less than $5 \%$ below about $700 \mathrm{hPa}$ ) in all simulations, and increases with altitude to $\approx 40 \%$ around $300 \mathrm{hPa}$. The maximum at high altitudes in the $\mathrm{SH}$ results from the transport of pollution in the middle troposphere from the $\mathrm{SH}$ lower latitudes and from the NH (see also Spracklen et al., 2005a).

When the empirical boundary layer nucleation scheme is included in the BHN_EMP_PRIM case, the anthropogenic contribution to $\mathrm{CCN}$ concentrations in the boundary layer is $56 \%$, a decrease of 6 percentage points from the BHN_PRIM case. The decrease is large over oceanic regions strongly influenced by continental pollution (compare Fig. $5 \mathrm{~d}$ and $\mathrm{f}$, and Fig. 7b). For example, over the North Pacific, the inclusion of boundary layer nucleation decreases the anthropogenic fraction from $40 \%-60 \%$ in BHN_PRIM to $20-40 \%$ in BHN_EMP_PRIM. Over these regions, the relative increase in the $\mathrm{SO}_{2}$ concentration from the preindustrial to the present day simulation is small due to the strong natural contribution from the oxidation of DMS, while the relative increase in the primary-emitted particles is large due to the influence from continental pollution. Both of these factors lead to a smaller relative contribution from boundary layer nucleation to the $\mathrm{CCN}$ concentration in the PD compared to that in the PI atmosphere, which decreases the anthropogenic fraction of the $\mathrm{CCN}$ concentration. Over polluted continental regions, the effect of the empirical boundary layer nucleation scheme on the anthropogenic fraction of $\mathrm{CCN}$ is small.

In the cases which do not include any primary-emitted anthropogenic sulfate (BHN_EMP vs. BHN), the empirical boundary layer nucleation scheme increases the anthropogenic fraction of $\mathrm{CCN}$ by 1.5 percentage points from $44.9 \%$ in BHN to $46.4 \%$ in BHN_EMP in the boundary layer. This increase mainly occurs over continental regions (Fig. 7a), which contrasts with the cases that included primary-emitted sulfate particles. Over these continental regions, the relative increase in the $\mathrm{SO}_{2}$ concentration from the PI to the PD simulation is larger than the relative increase in primary-emitted particles, which leads to a larger contribution to the CCN concentration in the PD than in the PI atmosphere when the boundary layer nucleation mechanism is included, thereby increasing the anthropogenic fraction of $\mathrm{CCN}$. Decreases in the anthropogenic fraction of CCN over ocean regions are similar to the case when primary sulfate particles are emitted, but the decrease is not as large (compare Fig. 7a and b).
Binary homogeneous nucleation in the free troposphere decreases the annual-average anthropogenic fraction of CCN in the boundary layer compared to the case when it is only included in the boundary layer, from $46.3 \%$ in BLBHN to $43.9 \%$ in BHN. This decrease occurs mainly over tropical regions and over the $\mathrm{SH}$ (Fig. 7c). Over these regions, the relative increase in the $\mathrm{SO}_{2}$ concentration from the PI to the PD simulation is small due to strong natural contributions from the oxidation of DMS, which leads to a relatively smaller contribution from binary homogeneous nucleation to the CCN concentration in the PD than in the PI simulation. When these particles descend from the free troposphere into the boundary layer, they decrease the anthropogenic fraction of CCN. In contrast, over polluted continental regions and over much of the $\mathrm{NH}$, binary homogeneous nucleation in the free troposphere increases the anthropogenic fraction of $\mathrm{CCN}$ in the boundary layer. Over these continental regions, the relative increase in the $\mathrm{SO}_{2}$ concentration from the PI to the PD simulation is larger than the relative increase in primary-emitted particles, which leads to a relatively larger contribution from binary homogeneous nucleation to the $\mathrm{CCN}$ concentration in the PD than in the PI simulation, leading to the increase in the anthropogenic fraction of $\mathrm{CCN}$ concentrations over continental regions and throughout much of the NH. For the cases that include the empirical boundary layer nucleation scheme, the effect of binary homogeneous nucleation in the FT is much smaller and the globally-averaged anthropogenic fraction of $\mathrm{CCN}$ in the boundary layer is almost the same: $46.8 \%$ in EMP, and $46.4 \%$ in BHN_EMP (Fig. 7d) In these scenarios, the CCN concentrations in the boundary layer are mainly determined by the empirical boundary layer nucleation scheme together with the primary-emitted particles, and therefore the effect of binary homogeneous nucleation in the FT on the $\mathrm{CCN}$ concentration in the boundary layer is small.

Binary homogeneous nucleation in the FT has an important impact on the anthropogenic fraction of $\mathrm{CCN}$ in the free troposphere (Fig. 6a vs. b and Fig. 6d vs. e). It increases the anthropogenic fraction of CCN in the middle and upper troposphere over the $\mathrm{NH}$. Over those regions, BHN is an important source of aerosol particles (Fig. 2a vs. b and Fig. $2 \mathrm{~d}$ vs. e), and the relative increase in the $\mathrm{SO}_{2}$ concentration from the PI to the PD simulation is larger than the relative increase in primary-emitted particles. For scenarios without boundary layer nucleation (Fig. 6a vs. b), BHN in the FT decreases the anthropogenic fraction of $\mathrm{CCN}$ concentration over most of the SH. This is because the relative increase in the $\mathrm{SO}_{2}$ concentration from the PI to the PD in the $\mathrm{SH}$ is somewhat smaller than the relative increase in primary particles

This comparison suggests that the competition for sulfuric acid gas between primary particles and nucleation determines whether the inclusion of a nucleation mechanism (boundary layer nucleation or free troposphere nucleation) in the model increases or decreases the anthropogenic fraction 

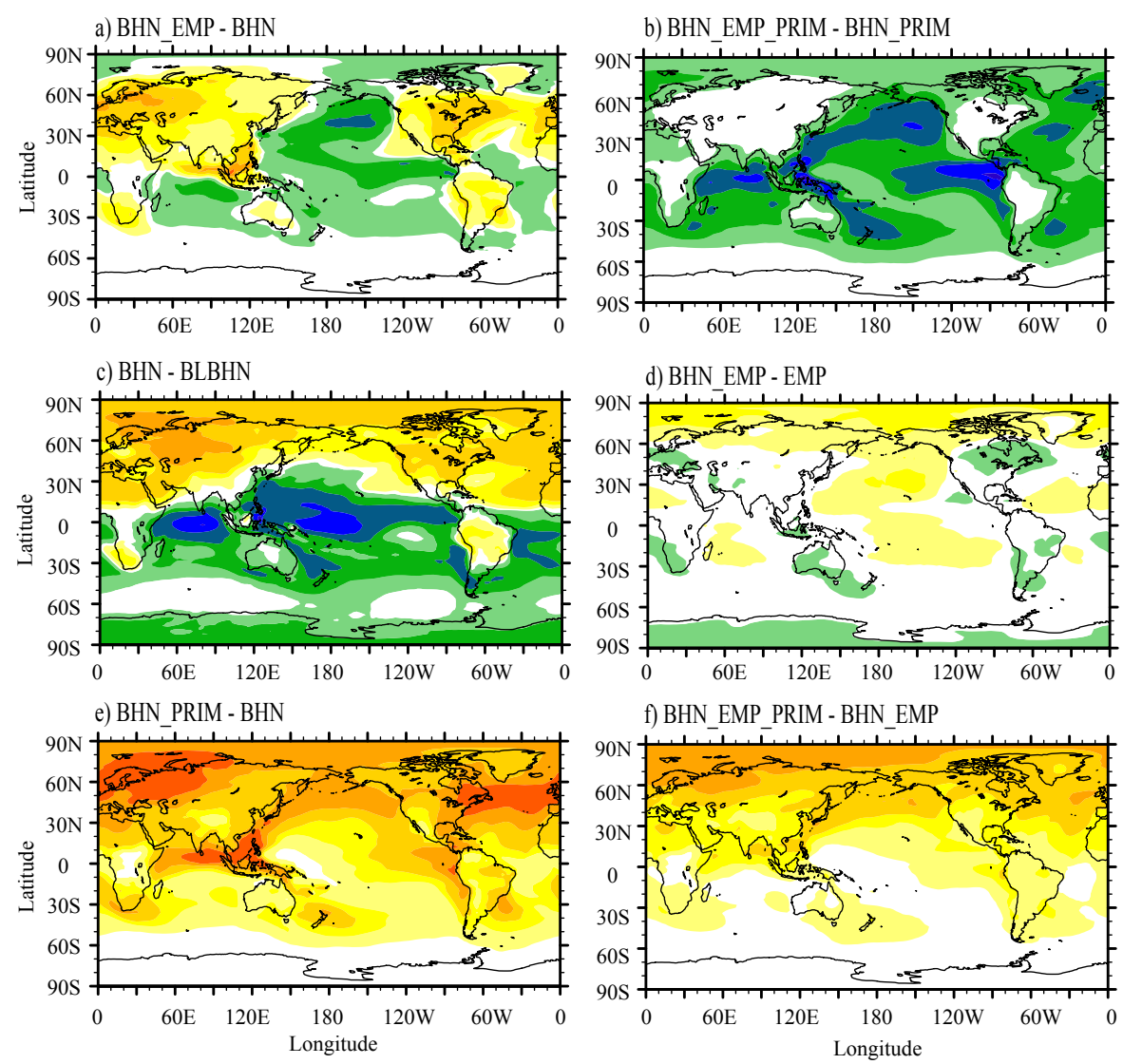

Fig. 7. Difference in annual-average anthropogenic fraction of $\mathrm{CCN}$ concentrations between difference cases.
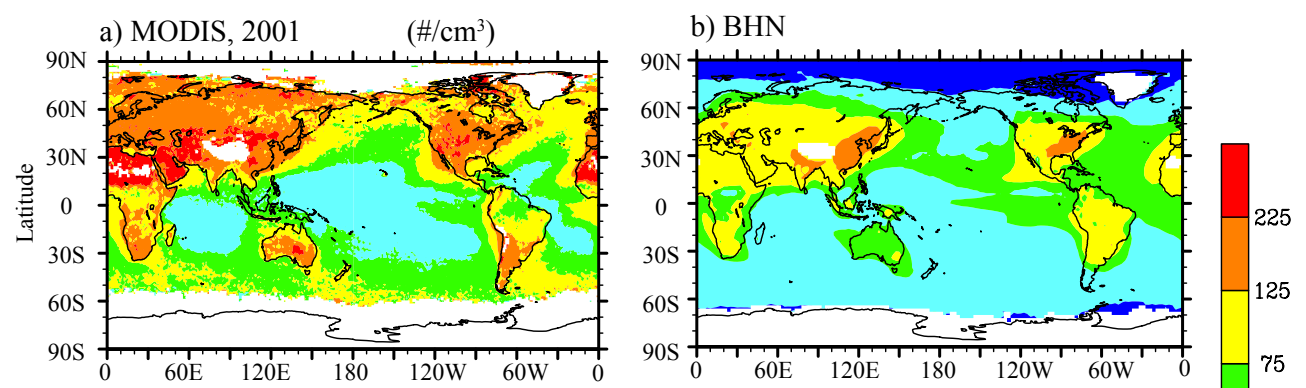

c) BHN_PRIM
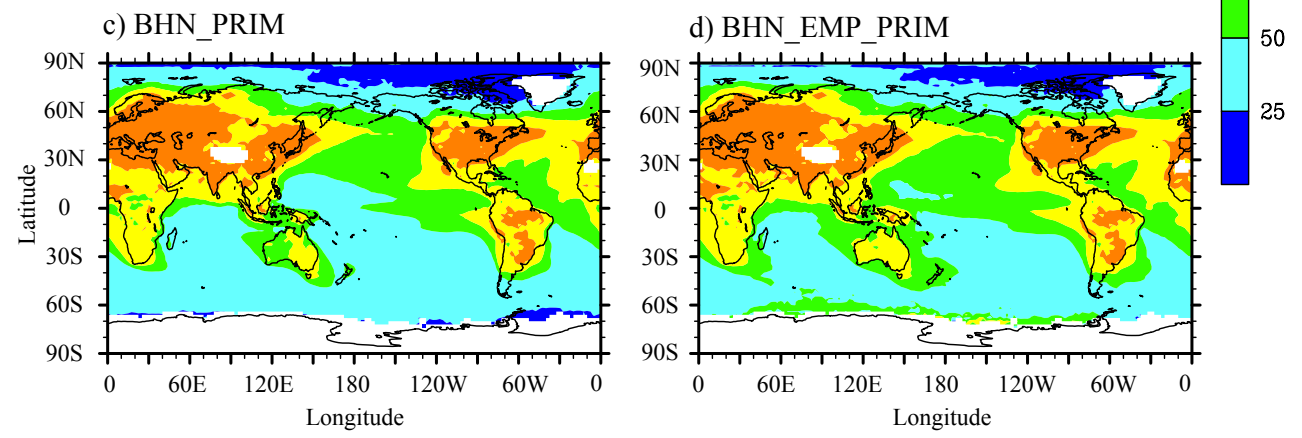

Fig. 8. Annual-average cloud top droplet number concentrations $\left(\mathrm{cm}^{-3}\right)$ derived from (a) MODIS (Quaas et al., 2006), (b) BHN, (c) BHN_PRIM and (d) BHN_EMP_PRIM. 
of the $\mathrm{CCN}$ particles. When the relative increase in the precursor gas species $\left(\mathrm{SO}_{2}\right)$ is large and the relative increase in primary particles is not that large, the inclusion of nucleation tends to increase the anthropogenic fraction. In contrast, when the relative increase in the precursor gas species $\left(\mathrm{SO}_{2}\right)$ is small but the relative increase in primary particles is not that small, the inclusion of nucleation tends to decrease the anthropogenic fraction.

The effect of including primary-emitted sulfate particles on the anthropogenic fraction of CCN particles is large. For the cases that don't include the boundary layer nucleation scheme, the inclusion of primary-emitted sulfate particles increases the annual-average anthropogenic fraction of $\mathrm{CCN}$ from $44 \%$ in BHN to $62 \%$ in BHN_PRIM. Large increases in the anthropogenic fraction occur over Europe, South East Asia, and regions of continental outflow over the North Atlantic (Fig. 7e). This large increase can be explained by two factors: first, primary-emitted sulfate (at least at the sizes assumed here) forms $\mathrm{CCN}$-size particles more efficiently than do particles that nucleate from gas phase $\mathrm{H}_{2} \mathrm{SO}_{4}$, and second, the percentage change in primary-emitted sulfate particles between the PD and PI simulations is larger than the percentage change in other primary particles (carbonaceous aerosols, dust and sea salt) between the PD and PI simulations. The inclusion of the boundary layer nucleation scheme partly offsets this large increase in the anthropogenic fraction from primary-emitted sulfate, and leads to a smaller increase in the anthropogenic fraction of CCN due to primary sulfate than that in the case without boundary layer nucleation. The increase in the boundary layer is 10 percentage points (from $46 \%$ in BHN_EMP to 56\% in BHN_EMP_PRIM) compared to an increase of 18 percentage points without boundary layer nucleation. The zonal annual-average anthropogenic fraction of CCN shows that the inclusion of primary-emitted sulfate particles also increases the anthropogenic fraction of $\mathrm{CCN}$ in the middle to upper troposphere in the NH (Fig. $6 \mathrm{c}$ vs. b or Fig. $6 \mathrm{f}$ vs. e). These results indicate that primary-emitted sulfate particles not only increase $\mathrm{CCN}$ concentrations in the PD significantly, but also increase the anthropogenic fraction of CCN concentrations significantly.

\section{Cloud droplet number concentrations and the first aerosol indirect forcing}

The simulated cloud top droplet number concentration for lower level warm clouds is shown in Fig. 8 along with satellite observations. The satellite data was derived from version 4 of the Moderate Resolution Imaging Spectroradiometer (MODIS) aboard the Terra satellite (Platnick et al., 2003) by Quaas et al. (2006). The MODIS cloud products include both cloud optical depth and cloud droplet effective radius, and Quaas et al. (2006) diagnosed droplet number from these variables assuming adiabatic clouds. The simulated cloud droplet number concentration at cloud top was diagnosed in the model using the ISCCP cloud simulator (Klein and Jacob, 1999; Webb et al., 2000) which emulates the way nadirlooking satellites measure clouds, and facilitates the comparison of the model data with satellite observations. For both the satellite and simulated data, only warm $(\mathrm{T}>273 \mathrm{~K})$ and low level (pressure $>640 \mathrm{hPa}$ ) clouds are sampled. The simulated data is sampled at each time step (every $30 \mathrm{~min}$ ).

The magnitude and spatial distribution of cloud-top droplet number from the BHN_PRIM case agrees better with the MODIS data than that from the BHN case. The simulated cloud droplet number concentration is larger over land than over the ocean in BHN_PRIM, because of the larger anthropogenic emissions over land with concentrations between 75 and $225 / \mathrm{cm}^{3}$ over land and between 25 and $75 / \mathrm{cm}^{3}$ over ocean. However, the model generally has a smaller cloud droplet number concentration, and simulates a smaller land/ocean contrast than that in the observation. In the $\mathrm{SH}$ between $40^{\circ}$ and $60^{\circ}$, the simulated cloud droplet number concentration is less than $50 / \mathrm{cm}^{3}$ while the measured cloud droplet number from MODIS is about $75 / \mathrm{cm}^{3}$. The high cloud droplet number concentration observed over this region in MODIS is also consistent with the high number concentration of CCN derived by Vallina et al. (2007) from the MODIS aerosol optical depth.

The inclusion of the empirical boundary layer nucleation scheme (BHN_EMP_PRIM) improves the comparison with MODIS cloud drop number concentration compared to the BHN_PRIM case. However, this version also underestimates the observed cloud droplet number concentrations in the $40^{\circ}$ and $60^{\circ} \mathrm{S}$ latitude belt. Pierce and Adams (2006) showed that the inclusion of a source of ultrafine sea salt particles can increase the simulated cloud droplet number concentration resulting from the condensational growth of ultrafine particles into CCN-size particles. The absence of condensable organic species from biogenic emissions in the IMPACT model may also cause an underestimate of the growth of small particles into $\mathrm{CCN}$-sized particles and contribute to the underestimation shown in Fig. 8. Recent studies (e.g., Vaattovaara et al., 2006) from observational data have shown that the formation of the secondary organic aerosols can contribute to the growth of recently formed particles.

Figure 9 shows the simulated change in cloud top effective radius from anthropogenic aerosols and the 1st aerosol indirect forcing for the BHN_PRIM case. Anthropogenic aerosols decrease the global average cloud top effective radius by $1.20 \mu \mathrm{m}$ with larger decreases over land and smaller decreases over ocean. The 1st aerosol indirect forcing is $-2.03 \mathrm{~W} / \mathrm{m}^{2}$ in this case. The spatial distribution of the first indirect forcing is determined by the change in the cloud top effective radius and, to a lesser extent, by the cloud forcing. The maximum in the first aerosol indirect forcing occurs over the north Pacific which is caused by the combination of the strong decrease in the cloud effective radius and strong cloud forcing over this region. 

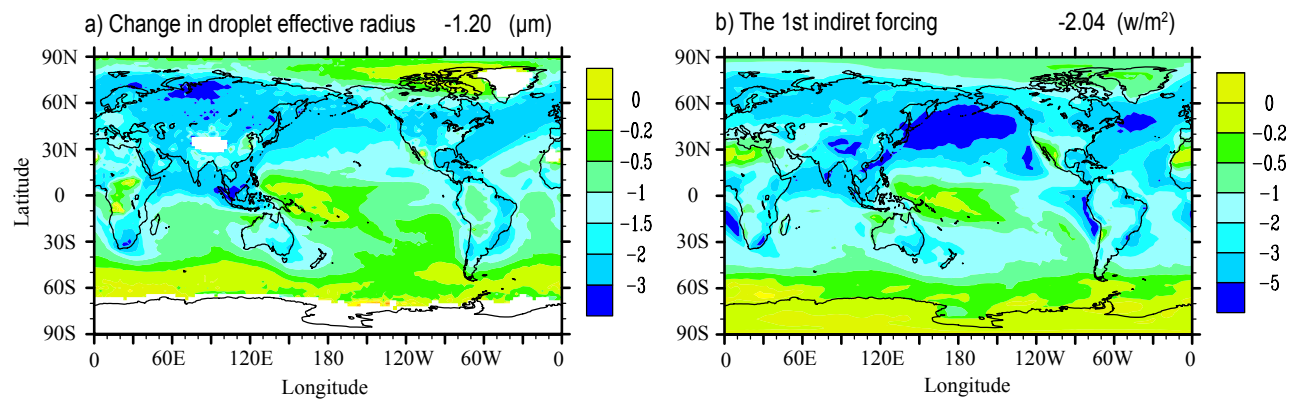

Fig. 9. (a) The change in the annual-average cloud top effective radius from anthropogenic emissions and (b) Annual-average 1st AIE in the BHN_PRIM case. The values given in the title are global averages.

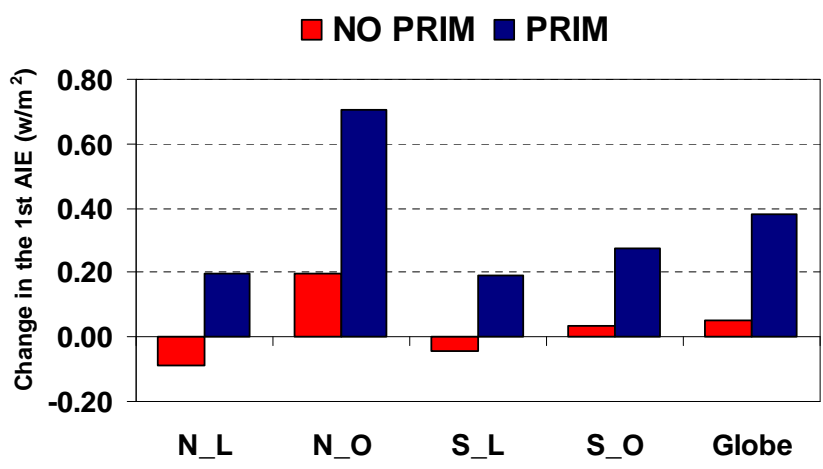

Fig. 10. Change in the simulated annual-average 1st AIE from including the empirical boundary layer nucleation mechanism in five regions: N_L: over Northern Hemisphere land; N_O: over Northern Hemisphere oceans; S_L: over Southern Hemisphere land; S_O: over Southern Hemisphere oceans; Global: global average (Red bar: the difference between BHN_EMP and BHN; Blue bar: the difference between BHN_EMP_PRIM and BHN_PRIM).

Figure 10 shows the change in the simulated 1st AIE from including the empirical boundary layer nucleation mechanism in five regions: $\mathrm{NH}$ land, $\mathrm{NH}$ oceans, $\mathrm{SH}$ land, $\mathrm{SH}$ oceans and the global average. These changes are consistent with the spatial pattern of the change in the simulated anthropogenic fraction of $\mathrm{CCN}$ shown in Fig. 7a and b. The 1 st aerosol indirect forcing is only $-1.65 \mathrm{~W} / \mathrm{m}^{2}$ in the BHN_EMP_PRIM case, a decrease of $0.38 \mathrm{~W} / \mathrm{m}^{2}$ in absolute magnitude from the BHN_PRIM case, as shown in Fig. 10 and in Table 5. This decrease occurs over most regions with the largest decrease over oceanic regions in the $\mathrm{NH}$, which comes from the decrease in the simulated anthropogenic fraction of CCN (Fig. 7b). In the cases without any primary-emitted sulfate particles, the inclusion of the empirical boundary layer nucleation scheme changes the global average forcing only slightly: from $-1.55 \mathrm{~W} / \mathrm{m}^{2}$ in BHN to $-1.49 \mathrm{~W} / \mathrm{m}^{2}$ in BHN_EMP, which is due to increases in the (negative) forcing over land and decreases over the ocean (Fig. 10). The inclusion of the empirical boundary layer nucleation scheme changes the spatial pattern of the first indi- rect forcing and shifts more of the contribution of the 1st AIE to land (i.e. the changes are more positive over the oceans in Fig. 10). This suggests the importance of including a boundary layer nucleation mechanism in the estimation of the global aerosol indirect forcing.

Figure 11 shows the change in the zonal mean annualaverage 1st AIE and the change in the zonal annual-average anthropogenic fraction of $\mathrm{CCN}$ from including primaryemitted sulfate particles. The inclusion of primary-emitted sulfate particles has a large impact on the first aerosol indirect forcing, which is consistent with its impact on the anthropogenic fraction of $\mathrm{CCN}$ as shown in Fig. 7e and f. For the cases without the empirical boundary layer nucleation scheme, the inclusion of primary-emitted sulfate particles changes the forcing from $-1.55 \mathrm{w} / \mathrm{m}^{2}$ in BHN to $-2.03 \mathrm{w} / \mathrm{m}^{2}$ in BHN_PRIM (Table 5). For the scenario with the empirical boundary layer nucleation scheme, the effect of including primary-emitted sulfate particles on the 1st indirect forcing is smaller, only increasing the magnitude of the forcing from $-1.49 \mathrm{~W} / \mathrm{m}^{2}$ in the BHN_EMP case to $-1.65 \mathrm{~W} / \mathrm{m}^{2}$ in the BHN_EMP_PRIM case (Table 5). The largest increases take place in the middle latitudes of the $\mathrm{NH}$ where anthropogenic sulfur has the largest contribution to the total sulfur (Fig. 11). This suggests that the treatment of sub-grid scale nucleation processes by including primary-emitted sulfate particles in the model introduces a large uncertainty in the estimation of the aerosol indirect forcing.

Binary homogeneous nucleation in the FT increases the forcing from $-1.22 \mathrm{~W} / \mathrm{m}^{2}$ in the EMP case to $-1.49 \mathrm{~W} / \mathrm{m}^{2}$ in the BHN_EMP case (Table 5). Although the change in the anthropogenic fraction of $\mathrm{CCN}$ in the boundary layer is small between these two cases, the vertical profiles of the anthropogenic fraction of $\mathrm{CCN}$ show an increase when binary homogeneous nucleation in the FT is included (Fig. 6d and e), which may explain the increase in the 1st indirect forcing. However, when there is no boundary layer nucleation, the inclusion of binary homogeneous nucleation in the FT doubles the forcing from $-0.81 \mathrm{~W} / \mathrm{m}^{2}$ in BLBHN to $-1.55 \mathrm{~W} / \mathrm{m}^{2}$ in BHN (Table 5). This large increase is caused by the unrealistically low droplet number concentrations simulated in 

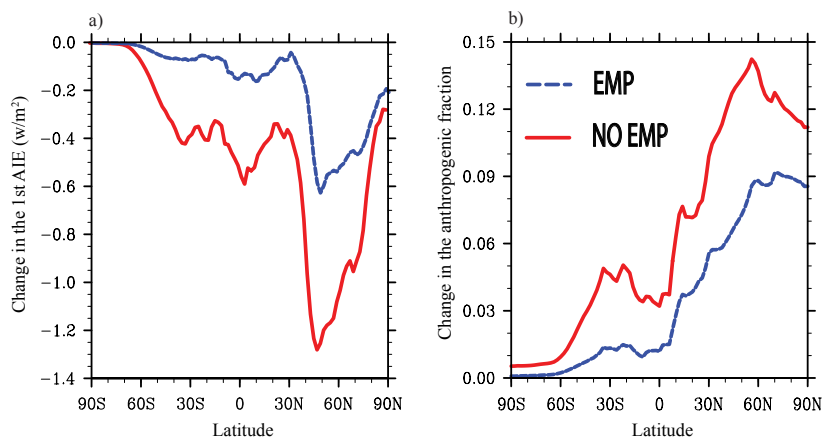

Fig. 11. (a) Change in the zonal mean annual-average 1st AIE and (b) the change in the zonal annual-average anthropogenic fraction of CCN (right panel) from including primary-emitted sulfate particles (Red line: the difference between BHN_PRIM and BHN; Blue line: the difference between BHN_EMP_PRIM and BHN_EMP).

the BLBHN case. In our calculation, we set a lower limit to the cloud droplet number concentration of $20 \mathrm{~cm}^{-3}$. Due to the low cloud droplet number concentration simulated in BLBHN, most regions have a constant cloud droplet number concentration of $20 \mathrm{~cm}^{-3}$ in both the present day and preindustrial simulations, which decreases the 1 st indirect forcing significantly.

The first aerosol indirect forcing calculated in this study is higher than that of most other studies (Foster et al. 2007). Here we explore how our estimation of the 1st aerosol indirect forcing depends on the assumption of the cloud types included in the indirect aerosol effect and the lower limit of the cloud droplet number concentrations. We compare different choices for these factors to the forcing calculated in the BHN_PRIM case averaged over four months (January, April, July and October) in order to save computer time.

As shown in Table 2.7 in Forster et al. (2007), different models have included different cloud types in their estimation of the 1st AIE. Some models only include warm clouds (e.g., Ming et al., 2005; Takemura et al., 2005), but other studies include both warm and mixed-phase clouds (e.g., Penner et al., 2006; Chen and Penner, 2005). Some models include only stratiform clouds (e.g., Suzuki et al., 2004), but other studies include both stratiform and convective clouds (e.g., Jones et al., 2001). In Fig. 12, in the simulation labeled WARM, we limited the 1st AIE to warm clouds only, which are clouds with temperature warmer than $273.15 \mathrm{~K}$. In the STRAT case, we limited the 1st AIE to stratiform clouds only. All other specifications in the WARM and STRAT cases are the same as those in the BHN_PRIM case. There is a $24 \%$ and $40 \%$ decrease in the 1st AIE in STRAT and in WARM, respectively, compared to that in BHN_PRIM (Fig. 12). Thus, the estimation of the 1st AIE is very sensitive to the cloud types included in the simulation. The large contribution from mixed-phase clouds to the estimation of the 1st AIE (40\%) depends, of course, on the fraction of these

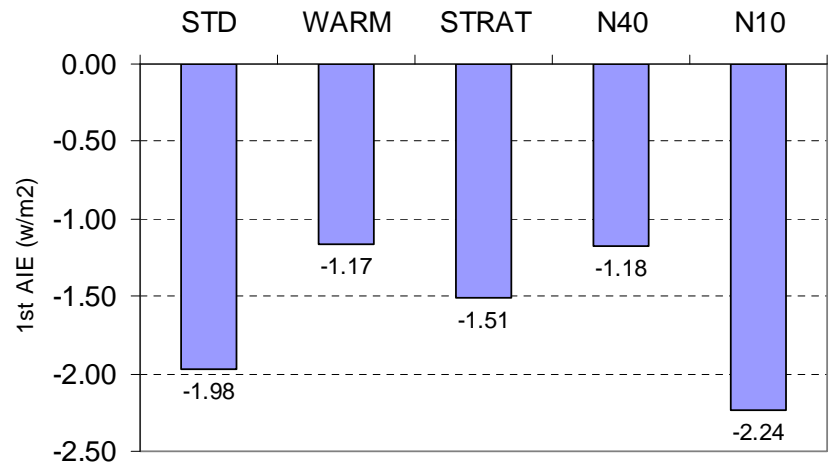

Fig. 12. The 1 st AIE from 5 different model configurations $\left(\mathrm{w} / \mathrm{m}^{2}\right)$ : STD, using the average from four months (January, April, July and October)in the case of BHN_PRIM; WARM: the same as STD but with only warm clouds (warmer than $273.15 \mathrm{~K}$ ) included; STRAT: the same as STD but with only stratiform clouds included; N40: the same as STD but with the minimum cloud droplet number set to $40 / \mathrm{cm}^{3}$; N10: the same as STD but with the minimum cloud droplet number set to $10 / \mathrm{cm}^{3}$.

clouds that are assumed to remain in the liquid phase. Since this fraction is simply specified in this model, the model sensitivity to this factor could be quite different with other formulations.

In the N40 and N10 simulations, we set the minimum cloud droplet number concentration to 40 and $10 / \mathrm{cm}^{3}$, respectively. In the N40 case, the 1st AIE is decreased by $40 \%$ compared with the BHN_PRIM case, and in the N10 case, the 1st AIE is increased by $13 \%$ compared with the BHN_PRIM case (Fig. 12). A minimum number concentration of $40 / \mathrm{cm}^{3}$ has been used in some model studies (e.g., Lohmann et al., 2007). Although it may be reasonable to set a minimum cloud droplet number concentration to determine background droplet number concentrations if the predicted aerosol number concentrations are too low, our sensitivity tests show that the exact value of the minimum droplet number concentration makes a large difference in the estimated AIE. Moreover, the effect of the minimum droplet number depends on the simulated cloud droplet number.

\section{Summary and discussion}

The effects of different nucleation parameterizations have not been included in global model studies of the aerosol indirect effect. Here, we used a global aerosol model that includes an empirical boundary layer nucleation scheme as well as binary homogeneous nucleation to explore how nucleation affects the concentration of $\mathrm{CCN}$ and aerosol indirect forcing. We also investigated how the inclusion of primary-emitted sulfate particles affects CCN concentrations and aerosol indirect forcing. 
The inclusion of the empirical boundary layer nucleation scheme improved the comparison of cloud top droplet number concentrations from the model with satellite data over the Southern Oceans, but the model still underestimates cloud top droplet number concentrations in the region from $30^{\circ} \mathrm{S}$ to $60^{\circ} \mathrm{S}$. This underestimation may come from the absence of ultrafine sea salt particles or from the absence of condensable organic species from marine biogenic emissions.

Our study showed that the effect of the empirical boundary layer nucleation scheme on $\mathrm{CCN}$ concentration depends in an important way on the assumed and simulated primary particles. Including the empirical boundary layer nucleation increases global average $\mathrm{CCN}$ concentrations in the boundary layer by $31.4 \%$ when the primary sulfate particles are excluded, and by $5.3 \%$ when primary-emitted sulfate particles are included. In the MBL over the tropics and in the SH, the empirical boundary layer nucleation scheme increases $\mathrm{CCN}$ concentrations in the PD simulation by $30-100 \%$ and this increase has little dependence on whether primary-emitted sulfate particles are or are not included since primary sulfate particles make only a small contribution to the primary particles over these regions. However, uncertainties in the emissions of natural primary particles (sea salt and dust) over these remote regions prevent us from making any further conclusion. For example, if the underestimation of the cloud droplet number concentration in the Southern Ocean results from an underestimation of natural primary particles (e.g., ultrafine sea salt particles), the effects of boundary layer nucleation may be overestimated over that region.

This study also shows that the inclusion of the empirical boundary layer nucleation scheme in the model decreases the effects of BHN in the FT on CCN concentrations in the MBL as well as the effects of primary sulfate particles. When no boundary layer nucleation is included, the inclusion of BHN in the FT in the model increases $\mathrm{CCN}$ concentrations in the MBL by more than $150 \%$, which is consistent with other model studies. However, when the empirical boundary layer nucleation scheme is included in the model, BHN in the FT has a much smaller effect on CCN concentrations. This suggests that, as long as boundary layer nucleation events occur as frequently as Eq. (1) suggests, BHN in the FT is not a critical factor in determining the $\mathrm{CCN}$ concentration in the MBL. The inclusion of primary-emitted sulfate particles always increases $\mathrm{CCN}$ concentrations in the boundary layer, although the inclusion of the empirical boundary layer nucleation scheme decreases the percentage increases in CCN associated with primary-emitted sulfate from $53 \%$ to $23 \%$.

Our study suggests that the effect of including a nucleation mechanism (either boundary layer nucleation or free troposphere nucleation) in the model on the anthropogenic fraction of the $\mathrm{CCN}$ particles and on the first aerosol indirect forcing largely depends on the competition for sulfuric acid gas between primary particles and nucleation. When the relative increase in the precursor gas species $\left(\mathrm{SO}_{2}\right)$ between the PD and PI simulations is large and the relative increase in pri- mary particles is not that large, the inclusion of nucleation tends to increase the anthropogenic fraction and to increase the aerosol indirect forcing. This is the case for the effect of boundary layer nucleation over the $\mathrm{NH}$ land when no primary sulfate is included (Fig. 7a, and Fig. 10) and for the effect of BHN over the $\mathrm{NH}$ land (Fig. 7c). In contrast, when the relative increase in the precursor gas species $\left(\mathrm{SO}_{2}\right)$ between the PD and PI simulations is small but the relative increase in primary particles is not that small, the inclusion of nucleation tends to decrease the anthropogenic fraction and to decrease the aerosol indirect forcing. This is the case for the effect of the boundary layer nucleation over ocean regions (Fig. 7a, b and Fig. 10), and for the effect of BHN over the SH (Fig. 7c). This contrast explains why the empirical boundary layer nucleation scheme changes the spatial pattern of the first indirect forcing and shifts more of the contribution of the 1st AIE to land (Fig. 10). The magnitude of the relative increase in $\mathrm{SO}_{2}$ and primary particles between the PD and PI simulations causes a large decrease in the first indirect forcing over ocean and small decreases or even increases in the first indirect forcing over land in the simulations with boundary layer nucleation compared to those without boundary layer nucleation.

In this study, the nucleation rate from boundary layer nucleation only depends on the sulfuric acid gas concentrations, and the meteorological fields are the same for both the PI and PD simulations. So the primary particles and precursor gas species are the two most critical factors in determining the effects of nucleation on the anthropogenic fraction of $\mathrm{CCN}$ particles and on the aerosol indirect forcing. However, if boundary layer nucleation also depends on some other factors and if the meteorological fields are changed as a result of global warming, the effects of including a boundary layer nucleation mechanism on aerosol indirect forcing can differ from that calculated here. For example, the ion-mediated nucleation mechanism suggested by Yu (2006) leads to less nucleation at higher temperatures (Yu et al., 2008b). This suggests that including a boundary layer nucleation scheme would have lead to a smaller increase and a larger decrease in the anthropogenic fraction of CCN than that in this study, if this ion-mediated nucleation mechanism were used and the increase in temperature from the PI to the PD were included.

In this study, a 2-mode representation (nucleation/Aitken mode and accumulation mode) of the sulfate aerosol size distribution is used to simulate the effects of nucleation events from both boundary layer nucleation and BHN. As shown in Wang09, a 3-mode representation with an additional mode representing nucleation sizes (radius $<5 \mathrm{~nm}$ ) produces fewer Aitken mode particles and more accumulation mode particles in the upper troposphere because of the large amount of freshly nucleated particles from BHN. However, the 3-mode representation has a smaller effect on the accumulation mode particles in the boundary layer even when boundary layer nucleation is included. This is partly due to the fact that the aerosol particles generated from boundary layer nucleation 
are grown by condensation up to a size of $3 \mathrm{~nm}$ and have lower number concentrations in the nucleation mode compared with those from BHN. In addition, primary particles are important sources for accumulation mode particles in the boundary layer, whereas the growth of particles from the nucleation mode is important in the free troposphere. As a result, the effects of different size distribution treatments (3mode vs. 2-mode) is small. Since accumulation mode particles in the boundary layer are the focus of this study, we would expect the 3-mode representation to have small effects on the results reported here.

Our study also shows that the inclusion of primary-emitted sulfate increases the anthropogenic fraction of CCN concentrations and the first aerosol indirect forcing significantly, because primary-emitted sulfate forms CCN-size particles more efficiently than do particles that nucleate from the gas phase. The percentage change in primary-emitted sulfate particles between PD and PI simulatons is larger than the percentage change in other primary particles. This suggests that the treatment of sub-grid scale nucleation processes by including primary-emitted sulfate particles in the model introduces a large uncertainty in the estimation of the aerosol indirect forcing. When boundary layer nucleation is included, the effect of primary-emitted sulfate particles is smaller.

In summary, this study shows the importance of different nucleation mechanisms and the inclusion of primary sulfate particles on the $\mathrm{CCN}$ concentrations and on the aerosol indirect forcing. Better parameterizations for the treatment of sub-grid scale nucleation processes as well as the mechanisms of aerosol nucleation are urgently needed.

Acknowledgements. The authors acknowledge partial support from the National Science Foundation under grant number ATM0333016 and the support of NASA from grants NNG04GC01G and NNG04GH47G. The authors also thank three anonymous reviewers and Dr. J Kazil for their helpful comments, which have allowed us to improve and clarify the manuscript.

Edited by: K. Lehtinen

\section{References}

Abdul-Razzak, H. and Ghan, S. J.: A parameterization of aerosol activation 2. Multiple aerosol types, J. Geophys. Res., 105, 6837-6844, 2000.

Abdul-Razzak, H. and Ghan, S. J.: A parameterization of aerosol activation - 3. Sectional representation, J. Geophys. Res., 107, 4026, doi:10.1029/2001JD000483, 2002.

Adams, P. J. and Seinfeld, J. H.: Predicting global aerosol size distributions in general circulation models, J. Geophys. Res., 107, 4370, doi:10.1029/2001JD001010, 2002.

Adams, P. J. and Seinfeld, J. H.: Disproportionate impact of particulate emissions on global cloud condensation nuclei concentrations, Geophys. Res. Lett., 30, 1239, doi:10.1029/2002GL016303, 2003.
Andres, R. J. and Kasgnoc, A. D.: A time-averaged inventory of subaerial volcanic sulfur emissions, J. Geophys. Res., 103, 25251-25261, 1998.

Boville, B. A., Rasch, P. J., Hack, J. J., and McCaa, J. R.: Representation of clouds and precipitation processes in the community atmosphere model version 3 (cam3), J. Clim., 19, 2184-2198, 2006.

Chen, Y. and Penner, J. E.: Uncertainty analysis for estimates of the first indirect aerosol effect, Atmos. Chem. Phys., 5, 2935-2948, 2005, http://www.atmos-chem-phys.net/5/2935/2005/.

Clarke, A. D., Uehara, T., and Porter, J. N.: Lagrangian evolution of an aerosol column during the atlantic stratocumulus transition experiment, J. Geophys. Res., 101, 4351-4362, 1996.

Clarke, A. D., Davis, D., Kapustin, V. N., Eisele, F., Chen, G., Paluch, I., Lenschow, D., Bandy, A. R., Thornton, D., Moore, K., Mauldin, L., Tanner, D., Litchy, M., Carroll, M. A., Collins, J., and Albercook, C.: Particle nucleation in the tropical boundary layer and its coupling to marine sulfur sources, Science, 282, 89-92, 1998.

Clarke, A. D., Owens, S. R., and Zhou, J. C.: An ultrafine sea-salt flux from breaking waves: Implications for cloud condensation nuclei in the remote marine atmosphere, J. Geophys. Res., 111, D06202, doi:10.1029/2005JD006565, 2006.

Collins, W. D., Rasch, P. J., Boville, B. A., Hack, J. J., McCaa, J. R., Williamson, D. L., Briegleb, B. P., Bitz, C. M., Lin, S. J., and Zhang, M. H.: The formulation and atmospheric simulation of the community atmosphere model version 3 (cam3), J. Clim., 19, 2144-2161, 2006a.

Collins, W. D., Bitz, C. M., Blackmon, M. L., Bonan, G. B., Bretherton, C. S., Carton, J. A., Chang, P., Doney, S. C., Hack, J. J., Henderson, T. B., Kiehl, J. T., Large, W. G., McKenna, D. S., Santer, B. D., and Smith, R. D.: The community climate system model version 3 (ccsm3), J. Clim., 19, 2122-2143, 2006 b.

Easter, R. C., Ghan, S. J., Zhang, Y., Saylor, R. D., Chapman, E. G., Laulainen, N. S., Abdul-Razzak, H., Leung, L. R., Bian, X. D., and Zaveri, R. A.: Mirage: Model description and evaluation of aerosols and trace gases, J. Geophys. Res., 109, D20210, doi:10.1029/2004JD004571, 2004.

Forster, P., Ramaswamy, V., Artaxo, P., Berntsen, T., Betts, R., Fahey, D. W., Haywood, J., Lean, J., Lowe, D. C., Myhre, G., Nganga, J., Prinn, R., Raga, G., Schulz, M., and Dorland, R. V.: Changes in atmospheric constituents and in radiative forcing, in: Climate change 2007: The physical science basis. Contribution of working group $i$ to the fourth assessment report of the intergovernmental panel on climate change, edited by: Solomon, S., Qin, D., Manning, M., Chen, Z., M. Marquis, Averyt, K. B., Tignor, M., and Miller, H. L., Cambridge University Press, Cambridge, UK and New York, NY, USA, 2007.

Ghan, S. J., Leung, L. R., Easter, R. C., and AbdulRazzak, K.: Prediction of cloud droplet number in a general circulation model, J. Geophys. Res., 102, 21777-21794, 1997.

Ghan, S. J., Easter, R. C., Chapman, E. G., Abdul-Razzak, H., Zhang, Y., Leung, L. R., Laulainen, N. S., Saylor, R. D., and Zaveri, R. A.: A physically based estimate of radiative forcing by anthropogenic sulfate aerosol, J. Geophys. Res., 106, 52795293, 2001a.

Ghan, S., Laulainen, N., Easter, R., Wagener, R., Nemesure, S., Chapman, E., Zhang, Y., and Leung, R.: Evaluation of aerosol direct radiative forcing in mirage, J. Geophys. Res., 106, 5295- 
5316, 2001b.

Ginoux, P., Chin, M., Tegen, I., Prospero, J. M., Holben, B., Dubovik, O., and Lin, S. J.: Sources and distributions of dust aerosols simulated with the gocart model, J. Geophys. Res., 106, 20255-20273, 2001.

Ginoux, P., Prospero, J. M., Torres, O., and Chin, M.: Long-term simulation of global dust distribution with the gocart model: Correlation with north atlantic oscillation, Environ. Model. Software, 19, 113-128, 2004.

Gong, S. L., Barrie, L. A., and Blanchet, J. P.: Modeling sea-salt aerosols in the atmosphere .1. Model development, J. Geophys. Res., 102, 3805-3818, 1997.

Gong, S. L., Barrie, L. A., Blanchet, J. P., von Salzen, K., Lohmann, U., Lesins, G., Spacek, L., Zhang, L. M., Girard, E., Lin, H., Leaitch, R., Leighton, H., Chylek, P., and Huang, P.: Canadian aerosol module: A size-segregated simulation of atmospheric aerosol processes for climate and air quality models - 1. Module development, J. Geophys. Res., 108, 4007, doi:10.1029/2001JD002002, 2003.

Herzog, M., Weisenstein, D. K., and Penner, J. E.: A dynamic aerosol module for global chemical transport models: Model description, J. Geophys. Res., 109, D18202, doi:10.1029/2003jd004405, 2004.

Holtslag, A. A. M., and Boville, B. A.: Local versus nonlocal boundary-layer diffusion in a global climate model, J. Clim., 6, 1825-1842, 1993.

Hoppel, W. A., Frick, G. M., Fitzgerald, J. W., and Wattle, B. J.: A cloud chamber study of the effect that nonprecipitating water clouds have on the aerosol-size distribution, Aerosol Sci. Tech., 20, 1-30, 1994.

Ito, A. and Penner, J. E.: Historical emissions of carbonaceous aerosols from biomass and fossil fuel burning for the period 1870-2000, Global Biogeochem. Cycles, 19, GB2028, doi:10.1029/2004GB002374, 2005.

Jiang, H. L. and Cotton, W. R.: A diagnostic study of subgrid-scale activation, J. Geophys. Res., 110, D16107, doi:10.1029/2004JD005722, 2005.

Jones, A., Roberts, D. L., Woodage, M. J., and Johnson, C. E.: Indirect sulphate aerosol forcing in a climate model with an interactive sulphur cycle, J. Geophys. Res., 106, 20293-20310, 2001.

Kerminen, V. M. and Kulmala, M.: Analytical formulae connecting the "Real" And the "Apparent" Nucleation rate and the nuclei number concentration for atmospheric nucleation events, J. Aerosol Sci., 33, 609-622, 2002.

Kettle, A. J. and Andreae, M. O.: Flux of dimethylsulfide from the oceans: A comparison of updated data seas and flux models, J. Geophys. Res., 105, 26793-26808, 2000.

Klein, S. A. and Jakob, C.: Validation and sensitivities of frontal clouds simulated by the ecmwf model, Mon. Weather Rev., 127, 2514-2531, 1999.

Korhonen, P., Kulmala, M., Laaksonen, A., Viisanen, Y., McGraw, R., and Seinfeld, J. H.: Ternary nucleation of h2so4, nh3, and h2o in the atmosphere, J. Geophys. Res., 104, 26349-26353, 1999.

Kuang, C., McMurry, P. H., McCormick, A. V., and Eisele, F. L.: Dependence of nucleation rates on sulfuric acid vapor concentration in diverse atmospheric locations, J. Geophys. Res., 113, D10209, doi:10.1029/2007JD009253, 2008.

Kulmala, M., Lehtinen, K. E. J., and Laaksonen, A.: Cluster activation theory as an explanation of the linear dependence between formation rate of $3 \mathrm{~nm}$ particles and sulphuric acid concentration, Atmos. Chem. Phys., 6, 787-793, 2006,

http://www.atmos-chem-phys.net/6/787/2006/.

Kulmala, M., Riipinen, I., Sipila, M., Manninen, H. E., Petaja, T., Junninen, H., Dal Maso, M., Mordas, G., Mirme, A., Vana, M., Hirsikko, A., Laakso, L., Harrison, R. M., Hanson, I., Leung, C., Lehtinen, K. E. J., and Kerminen, V. M.: Toward direct measurement of atmospheric nucleation, Science, 318, 89-92, 2007.

Laaksonen, A., Hamed, A., Joutsensaari, J., Hiltunen, L., Cavalli, F., Junkermann, W., Asmi, A., Fuzzi, S., and Facchini, M. C.: Cloud condensation nucleus production from nucleation events at a highly polluted region, Geophys. Res. Lett., 32, L06812, doi:10.1029/2004GL022092, 2005.

Lauer, A., Hendricks, J., Ackermann, I., Schell, B., Hass, H., and Metzger, S.: Simulating aerosol microphysics with the echam/made $\mathrm{gcm}$ - part i: Model description and comparison with observations, Atmos. Chem. Phys., 5, 3251-3276, 2005 , http://www.atmos-chem-phys.net/5/3251/2005/.

Lihavainen, H., Kerminen, V. M., Komppula, M., Hatakka, J., Aaltonen, V., Kulmala, M., and Viisanen, Y.: Production of "Potential" Cloud condensation nuclei associated with atmospheric new-particle formation in northern Finland, J. Geophys. Res., 108, 4782, doi:10.1029/2003JD003887, 2003.

Liu, X. H., Penner, J. E., and Herzog, M.: Global modeling of aerosol dynamics: Model description, evaluation, and interactions between sulfate and nonsulfate aerosols, J. Geophys. Res., 110, D18206, doi:10.1029/2004JD005674, 2005.

Lohmann, U., Feichter, J., Chuang, C. C., and Penner, J. E.: Prediction of the number of cloud droplets in the echam $\mathrm{gcm}, \mathrm{J}$. Geophys. Res., 104, 9169-9198, 1999.

Lohmann, U., Stier, P., Hoose, C., Ferrachat, S., Kloster, S., Roeckner, E., and Zhang, J.: Cloud microphysics and aerosol indirect effects in the global climate model echam5-ham, Atmos. Chem. Phys., 7, 3425-3446, 2007,

http://www.atmos-chem-phys.net/7/3425/2007/.

Lucas, D. D. and Akimoto, H.: Evaluating aerosol nucleation parameterizations in a global atmospheric model, Geophys. Res. Lett., 33, L10808, doi:10.1029/2006GL025672, 2006.

McNaughton, C. S., Clarke, A. D., Howell, S. G., Moore, K. G., Brekhovskikh, V., Weber, R. J., Orsini, D. A., Covert, D. S., Buzorius, G., Brechtel, F. J., Carmichael, G. R., Tang, Y. H., Eisele, F. L., Mauldin, R. L., Bandy, A. R., Thornton, D. C., and Blomquist, B.: Spatial distribution and size evolution of particles in Asian outflow: Significance of primary and secondary aerosols during ACE-Asia and TRACE-P, J. Geophys. Res., 109, D19S06, doi 10.1029/2003JD003528, 2004.

Ming, Y., Ramaswamy, V., Ginoux, P. A., Horowitz, L. W., and Russell, L. M.: Geophysical fluid dynamics laboratory general circulation model investigation of the indirect radiative effects of anthropogenic sulfate aerosol, J. Geophys. Res., 110, D22206, doi:10.1029/2005JD006161, 2005.

Morrison, H., Curry, J. A., and Khvorostyanov, V. I.: A new doublemoment microphysics parameterization for application in cloud and climate models. Part i: Description, J. Atmos. Sci., 62, 1665$1677,2005$.

O’Dowd, C. D., Hameri, K., Makela, J. M., Pirjola, L., Kulmala, M., Jennings, S. G., Berresheim, H., Hansson, H. C., de Leeuw, G., Kunz, G. J., Allen, A. G., Hewitt, C. N., Jackson, A., Viisanen, Y., and Hoffmann, T.: A dedicated study of new par- 
ticle formation and fate in the coastal environment (parforce): Overview of objectives and achievements, J. Geophys. Res., 107, 8108, doi:10.1029/2001JD000555, 2002a.

O’Dowd, C. D., Jimenez, J. L., Bahreini, R., Flagan, R. C., Seinfeld, J. H., Hameri, K., Pirjola, L., Kulmala, M., Jennings, S. G., and Hoffmann, T.: Marine aerosol formation from biogenic iodine emissions, Nature, 417, 632-636, 2002b.

Penner, J. E., Quaas, J., Storelvmo, T., Takemura, T., Boucher, O., Guo, H., Kirkevag, A., Kristjansson, J. E., and Seland, O.: Model intercomparison of indirect aerosol effects, Atmos. Chem. Phys., 6, 3391-3405, 2006, http://www.atmos-chemphys.net/6/3391/2006/.

Pierce, J. R. and Adams, P. J.: Global evaluation of ccn formation by direct emission of sea salt and growth of ultrafine sea salt, J. Geophys. Res., 111, D06203, doi:10.1029/2005JD006186, 2006.

Pierce, J. R., Chen, K., and Adams, P. J.: Contribution of primary carbonaceous aerosol to cloud condensation nuclei: Processes and uncertainties evaluated with a global aerosol microphysics model, Atmos. Chem. Phys., 7, 5447-5466, 2007,

http://www.atmos-chem-phys.net/7/5447/2007/.

Platnick, S., King, M. D., Ackerman, S. A., Menzel, W. P., Baum, B. A., Riedi, J. C., and Frey, R. A.: The modis cloud products: Algorithms and examples from terra, IEEE T. Geosci. Remote, 41, 459-473, 2003.

Quaas, J., Boucher, O., and Lohmann, U.: Constraining the total aerosol indirect effect in the $1 \mathrm{mdz}$ and echam $4 \mathrm{gcms}$ using modis satellite data, Atmos. Chem. Phys., 6, 947-955, 2006, http://www.atmos-chem-phys.net/6/947/2006/.

Raes, F., Van Dingenen, R., Vignati, E., Wilson, J., Putaud, J. P., Seinfeld, J. H., and Adams, P.: Formation and cycling of aerosols in the global troposphere, Atmos. Environ., 34, 4215-4240, 2000.

Riipinen, I., Sihto, S. L., Kulmala, M., Arnold, F., Dal Maso, M., Birmili, W., Saarnio, K., Teinila, K., Kerminen, V. M., Laaksonen, A., and Lehtinen, K. E. J.: Connections between atmospheric sulphuric acid and new particle formation during quest iii-iv campaigns in heidelberg and hyyti, Atmos. Chem. Phys., 7, 1899-1914, 2007, http://www.atmos-chemphys.net/7/1899/2007/.

Rissler, J., Vestin, A., Swietlicki, E., Fisch, G., Zhou, J., Artaxo, P., and Andreae, M. O.: Size distribution and hygroscopic properties of aerosol particles from dry-season biomass burning in amazonia, Atmos. Chem. Phys., 6, 471-491, 2006,

http://www.atmos-chem-phys.net/6/471/2006/.

Rotstayn, L. D. and Liu, Y. G.: Sensitivity of the first indirect aerosol effect to an increase of cloud droplet spectral dispersion with droplet number concentration, J. Clim., 16, 3476-3481, 2003.

Sihto, S. L., Kulmala, M., Kerminen, V. M., Dal Maso, M., Petaja, T., Riipinen, I., Korhonen, H., Arnold, F., Janson, R., Boy, M., Laaksonen, A., and Lehtinen, K. E. J.: Atmospheric sulphuric acid and aerosol formation: Implications from atmospheric measurements for nucleation and early growth mechanisms, Atmos. Chem. Phys., 6, 4079-4091, 2006,

http://www.atmos-chem-phys.net/6/4079/2006/.

Singh, H. B., Anderson, B. E., Avery, M. A., Viezee, W., Chen, Y., Tabazadeh, A., Hamill, P., Pueschel, R., Fuelberg, H. E., and Hannan, J. R.: Global distribution and sources of volatile and nonvolatile aerosol in the remote troposphere, J. Geophys. Res., 107, 4121, doi:10.1029/2001JD000486, 2002.
Smith, S. J., Pitcher, H., and Wigley, T. M. L.: Global and regional anthropogenic sulfur dioxide emissions, Global Planet Change, 29, 99-119, 2001.

Smith, S., Andres, R., Conception, L., and Lurz, J.: Historical sulfur dioxide emissions 1850-2000: Methods and resutls, jgcri research report pnnl 14537, Paciific Northwest National Laboratory, Richland, WA, USA, 14537, 16, 2004.

Spracklen, D. V., Pringle, K. J., Carslaw, K. S., Chipperfield, M. P., and Mann, G. W.: A global off-line model of size-resolved aerosol microphysics: I. Model development and prediction of aerosol properties, Atmos. Chem. Phys., 5, 2227-2252, 2005a, http://www.atmos-chem-phys.net/5/2227/2005/.

Spracklen, D. V., Pringle, K. J., Carslaw, K. S., Chipperfield, M. P., and Mann, G. W.: A global off-line model of size-resolved aerosol microphysics: Ii. Identification of key uncertainties, Atmos. Chem. Phys., 5, 3233-3250, 2005b, http://www.atmos-chem-phys.net/5/3233/2005/.

Spracklen, D. V., Carslaw, K. S., Kulmala, M., Kerminen, V. M., Mann, G. W., and Sihto, S. L.: The contribution of boundary layer nucleation events to total particle concentrations on regional and global scales, Atmos. Chem. Phys., 6, 5631-5648, 2006, http://www.atmos-chem-phys.net/6/5631/2006/.

Spracklen, D. V., Carslaw, K. S., Kulmala, M., Kerminen, V. M., Sihto, S. L., Riipinen, I., Merikanto, J., Mann, G. W., Chipperfield, M. P., Wiedensohler, A., Birmili, W., and Lihavainen, H.: Contribution of particle formation to global cloud condensation nuclei concentrations, Geophys. Res. Lett., 35, L06808, doi:10.1029/2007GL033038, 2008.

Stier, P., Feichter, J., Kinne, S., Kloster, S., Vignati, E., Wilson, J., Ganzeveld, L., Tegen, I., Werner, M., Balkanski, Y., Schulz, M., Boucher, O., Minikin, A., and Petzold, A.: The aerosol-climate model echam5-ham, Atmos. Chem. Phys., 5, 1125-1156, 2005, http://www.atmos-chem-phys.net/5/1125/2005/.

Stier, P., Feichter, J., Kloster, S., Vignati, E., and Wilson, J.: Emission-induced nonlinearities in the global aerosol system: Results from the echam5-ham aerosol-climate model, J. Clim., 19, 3845-3862, 2006.

Storelvmo, T., Kristjansson, J. E., Ghan, S. J., Kirkevag, A., Seland, O., and Iversen, T.: Predicting cloud droplet number concentration in community atmosphere model (cam)-oslo, J. Geophys. Res., 111, D24208, doi:10.1029/2005jd006300, 2006.

Suzuki, K., Nakajima, T., Numaguti, A., Takemura, T., Kawamoto, K., and Higurashi, A.: A study of the aerosol effect on a cloud field with simultaneous use of $\mathrm{gcm}$ modeling and satellite observation, J. Atmos. Sci., 61, 179-194, 2004.

Takemura, T., Nozawa, T., Emori, S., Nakajima, T. Y., and Nakajima, T.: Simulation of climate response to aerosol direct and indirect effects with aerosol transport-radiation model, J. Geophys. Res., 110, D02202, doi:10.1029/2004JD005029, 2005.

Textor, C., Schulz, M., Guibert, S., Kinne, S., Balkanski, Y., Bauer, S., Berntsen, T., Berglen, T., Boucher, O., Chin, M., Dentener, F., Diehl, T., Easter, R., Feichter, H., Fillmore, D., Ghan, S., Ginoux, P., Gong, S., Kristjansson, J. E., Krol, M., Lauer, A., Lamarque, J. F., Liu, X., Montanaro, V., Myhre, G., Penner, J., Pitari, G., Reddy, S., Seland, O., Stier, P., Takemura, T., and Tie, $\mathrm{X}$.: Analysis and quantification of the diversities of aerosol life cycles within AEROCOM, Atmos. Chem. Phys., 6, 1777-1813, 2006, http://www.atmos-chem-phys.net/6/1777/2006/.

Twohy, C. H., Clement, C. F., Gandrud, B. W., Weinheimer, A. 
J., Campos, T. L., Baumgardner, D., Brune, W. H., Faloona, I., Sachse, G. W., Vay, S. A., and Tan, D.: Deep convection as a source of new particles in the midlatitude upper troposphere, J. Geophys. Res., 107, 4560, doi:10.1029/2001JD000323, 2002.

Vaattovaara, P., Huttunen, P. E., Yoon, Y. J., Joutsensaari, J., Lehtinen, K. E. J., O'Dowd, C. D., and Laaksonen, A.: The composition of nucleation and aitken modes particles during coastal nucleation events: Evidence for marine secondary organic contribution, Atmos. Chem. Phys., 6, 4601-4616, 2006, http://www.atmos-chem-phys.net/6/4601/2006/.

Vallina, S. M., Simo, R., Gasso, S., De Boyer-Montegut, C., del Rio, E., Jurado, E., and Dachs, J.: Analysis of a potential "Solar radiation dose-dimethylsulfide-cloud condensation nuclei" link from globally mapped seasonal correlations, Global Biogeochem. Сy., 21, GB2004, doi:10.1029/2006GB002787, 2007.

Van Dingenen, R., Raes, F., Putaud, J. P., Virkkula, A., and Mangoni, M.: Processes determining the relationship between aerosol number and non-sea-salt sulfate mass concentrations in the clean and perturbed marine boundary layer, J. Geophys. Res., 104, 8027-8038, 1999.

Vehkamäki, H., Kulmala, M., Napari, I., Lehtinen, K. E. J., Timmreck, C., Noppel, M., and Laaksonen, A.: An improved parameterization for sulfuric acid-water nucleation rates for tropospheric and stratospheric conditions, J. Geophys. Res., 107, 4622, doi:10.1029/2002JD002184, 2002.
Wang, M., Penner, J. E., and Liu, X.: The coupled IMPACT aerosol and NCAR CAM3 climate model: evaluation of predicted aerosol number and size distribution, J. Geophys. Res., doi:10.1029/2008JD010459, in press, 2009.

Webb, M., Senior, C., Bony, S., and Morcrette, J. J.: Combining erbe and isccp data to assess clouds in the hadley centre, ecmwf and lmd atmospheric climate models, Clim. Dynam., 17, 905922, 2001.

Wilson, J., Cuvelier, C., and Raes, F.: A modeling study of global mixed aerosol fields, J. Geophys. Res., 106, 34081-34108, 2001.

Yu, F.: From molecular clusters to nanoparticles: Secondgeneration ion-mediated nucleation model, Atmos. Chem. Phys., 6, 5193-5211, 2006, http://www.atmos-chemphys.net/6/5193/2006/.

Yu, F. and Turco, R.: Case studies of particle formation events observed in boreal forests: Implications for nucleation mechanims, Atmos. Chem. Phys., 8, 6085-6102, 2008a, http://www.atmos-chem-phys.net/8/6085/2008/.

Yu, F., Wang, Z., Luo, G., and Turco, R.: Ion-mediated nucleation as an important global source of tropospheric aerosols, Atmos. Chem. Phys., 8, 2537-2554, 2008b, http://www.atmos-chem-phys.net/8/2537/2008/.

Zhang, R. Y., Suh, I., Zhao, J., Zhang, D., Fortner, E. C., Tie, X. X., Molina, L. T., and Molina, M. J.: Atmospheric new particle formation enhanced by organic acids, Science, 304, 1487-1490, 2004. 